Review Article

\title{
Unraveling the Potential Role of Glutathione in Multiple Forms of Cell Death in Cancer Therapy
}

\author{
Huanhuan Lv $\mathbb{D}^{1,2,3,4,5}$ Chenxiao Zhen, ${ }^{1,2,5}$ Junyu Liu, ${ }^{1,2,5}$ Pengfei Yang, ${ }^{1,2,4,5}$ Lijiang Hu, ${ }^{3}$ \\ and Peng Shang $\mathbb{i D}^{2,4,5}$ \\ ${ }^{1}$ School of Life Sciences, Northwestern Polytechnical University, Xi'an, Shaanxi 710072, China \\ ${ }^{2}$ Research \& Development Institute of Northwestern Polytechnical University in Shenzhen, Shenzhen 518057, China \\ ${ }^{3}$ Zhejiang Heye Health Technology Co. Ltd., Anji, Zhejiang 313300, China \\ ${ }^{4}$ Research Centre of Microfluidic Chip for Health Care and Environmental Monitoring, Yangtze River Delta Research Institute of \\ Northwestern Polytechnical University in Taicang, Suzhou, Jiangsu 215400, China \\ ${ }^{5}$ Key Laboratory for Space Bioscience and Biotechnology, Northwestern Polytechnical University, Xi'an, Shaanxi 710072, China
}

Correspondence should be addressed to Peng Shang; shangpeng@nwpu.edu.cn

Received 11 April 2019; Accepted 21 May 2019; Published 10 June 2019

Guest Editor: Kanhaiya Singh

Copyright (C) 2019 Huanhuan Lv et al. This is an open access article distributed under the Creative Commons Attribution License, which permits unrestricted use, distribution, and reproduction in any medium, provided the original work is properly cited.

Glutathione is the principal intracellular antioxidant buffer against oxidative stress and mainly exists in the forms of reduced glutathione (GSH) and oxidized glutathione (GSSG). The processes of glutathione synthesis, transport, utilization, and metabolism are tightly controlled to maintain intracellular glutathione homeostasis and redox balance. As for cancer cells, they exhibit a greater ROS level than normal cells in order to meet the enhanced metabolism and vicious proliferation; meanwhile, they also have to develop an increased antioxidant defense system to cope with the higher oxidant state. Growing numbers of studies have implicated that altering the glutathione antioxidant system is associated with multiple forms of programmed cell death in cancer cells. In this review, we firstly focus on glutathione homeostasis from the perspectives of glutathione synthesis, distribution, transportation, and metabolism. Then, we discuss the function of glutathione in the antioxidant process. Afterwards, we also summarize the recent advance in the understanding of the mechanism by which glutathione plays a key role in multiple forms of programmed cell death, including apoptosis, necroptosis, ferroptosis, and autophagy. Finally, we highlight the glutathione-targeting therapeutic approaches toward cancers. A comprehensive review on the glutathione homeostasis and the role of glutathione depletion in programmed cell death provide insight into the redox-based research concerning cancer therapeutics.

\section{Introduction}

Glutathione is a thiol-containing tripeptide consisting of L-glutamate, cysteine, and glycine [1]. It is abundantly distributed in mammalian cells and mainly exists in the forms of reduced glutathione (GSH) and oxidized glutathione (glutathione disulfide (GSSG)). GSH is predominately distributed in the cytosol and to a lesser content in the subcellular organelles, such as the mitochondria, nucleus, and endoplasmic reticulum (ER). GSH takes part in many cellular metabolic activities including reactive oxygen species (ROS) removal, DNA and protein syntheses, and signal transduction $[2,3]$.
As for cancer cells, they need a greater ROS level than normal cells for the enhanced metabolism and vicious proliferation $[4,5]$. Nevertheless, the higher ROS level can also be counteracted by an increased activity of the antioxidant defense system which copes with the higher oxidant state. The GSH system is one of the major cellular antioxidant systems that cooperatively maintain and synergize the redox balance [6]. The increased GSH level has been observed in different human cancer cells and is an important contributor to cancer pathology and the resistance to anticancer therapy [7]. As a contrary, GSH depletion increases the susceptibility of cancer cells to various forms of programmed cell death and sensitivity to chemotherapies [8]. Consequently, the role of 


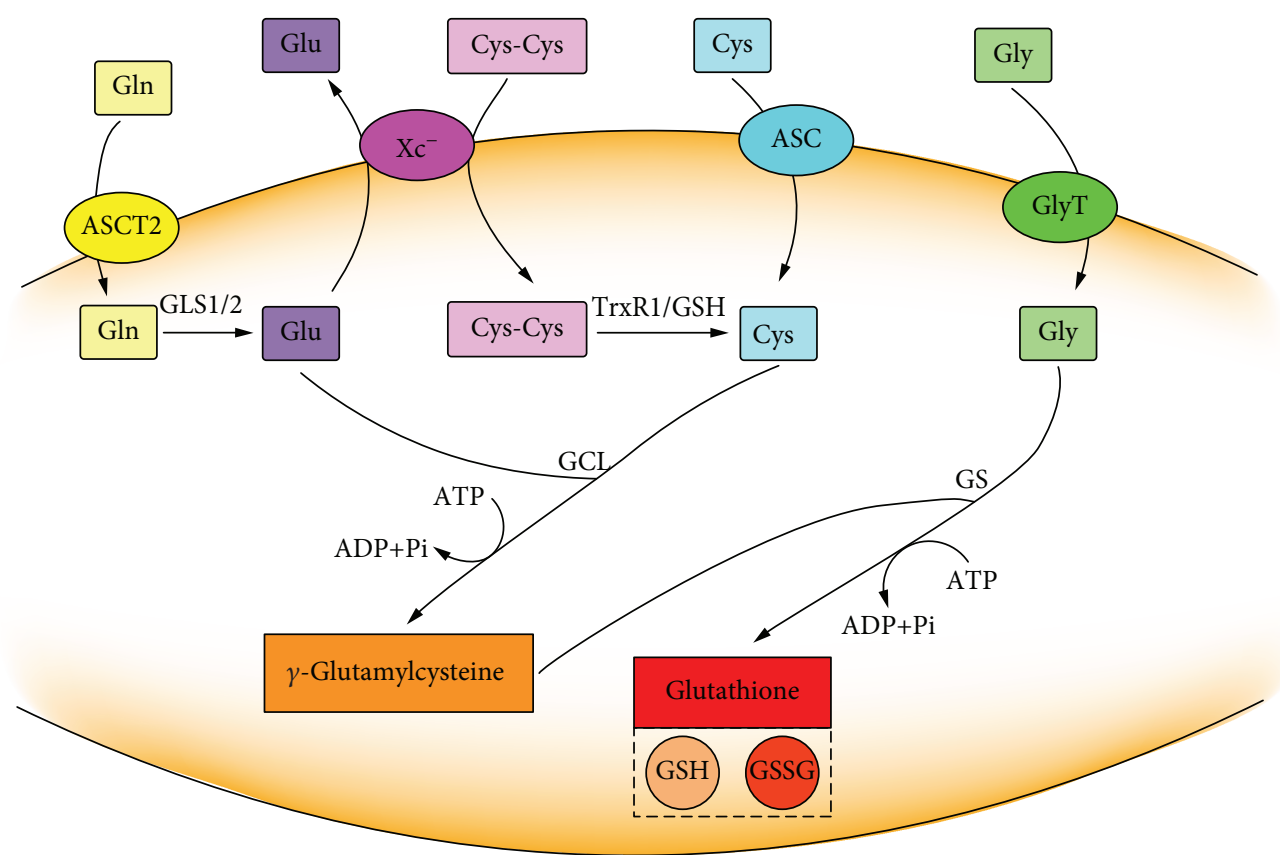

FIgURE 1: Two-step enzymatic reaction of glutathione synthesis. The first step is the coupling of L-glutamate and cysteine to produce $\gamma$-glutamylcysteine under the catalysis of glutamate-cysteine ligase (GCL). The second step is the coupling of $\gamma$-glutamylcysteine to glycine catalyzing by glutathione synthetase (GS). Each reaction consumes one ATP molecule. Glutathione exists in the forms of reduced GSH and oxidized GSSG.

GSH in the initiation of programmed cell death in cancer cells has been well implicated in accumulative studies. There are crosstalks and interrelationships between these different forms of programmed cell death induced by GSH.

Here, we highlight the GSH homeostasis, the relationship between GSH and oxidative stress, the recent findings of GSH depletion in multiple forms of programmed cell death, and GSH-targeting therapeutic approaches toward cancers. The review may help to better understand the role of GSH modulation in cell death and shed light on the possibility of finding new therapeutic approaches based on the redox system for cancers.

\section{GSH Homeostasis}

2.1. GSH Synthesis. The biosynthesis of glutathione was obtained by catalyzing of L-glutamate, cysteine, and glycine through continuous two-step enzymatic reactions which depend on ATP [9]. Glutamine is hydrolyzed by glutaminase (GLS1/2) to form glutamate after being absorbed into the cell via a transmembrane amino acid transporter (ASCT2). Cysteine can be directly absorbed by an amino acid transporter (ASC) or can be obtained by reduction of cystine absorbed by system $\mathrm{X}_{\mathrm{c}}{ }^{-}$. The intracellular glycine can be directly absorbed by a glycine transporter (GlyT). The synthesis of glutathione is through two-step enzymatic reactions by glutamate-cysteine ligase (GCL) and glutathione synthetase (GS) (Figure 1). In the first step, GCL catalyzes the reaction of cysteine with glutamate to produce $\gamma$-glutamylcysteine; next step, $\gamma$-glutamylcysteine is combined with glycine to produce glutathione under the catalysis of GS [10]. Since the concentration of $\gamma$-glutamylcysteine is negligible when GS is present, GCL determines the rate of GSH synthesis during this process [11].

Glutathione exists in the reduced GSH form and oxidized GSSG form. The content of glutathione is in a dynamic balance through the regulation of synthesis, utilization, metabolism, and efflux. Under physiological condition, GSH is the predominant form which is more than $98 \%$, while GSSG is less than $1 \%$ [12].

2.2. GSH Distribution. The glutathione-centered redox system participates in the redox signal network and controls cell growth, development, and oxidant defense [13]. In addition to the cytoplasm, glutathione also presents in various subcellular organelles, including the nucleus, mitochondria, and ER (Figure 2). There is a significant difference in glutathione distribution among these subcellular organelles $[14,15]$. The distribution of glutathione in different intervals is critical because it establishes a redox environment that supports various metabolic and signaling events [16]. The maintenance of redox homeostasis of the nucleus, mitochondria, ER, and other organelles as well as the extracellular environment is inseparable from glutathione.

2.2.1. Cytosolic GSH. In mammalian cells, glutathione is exclusively synthesized in the cytosol and about $85 \%$ of it remains where it was synthesized $[17,18]$. In the cytosol, glutathione is mainly in the reduced form. The ratio of GSH:GSSG in the cytosol is conservatively estimated at about $10000: 1 \sim 50000: 1$ [19]. Reports show that the concentration of the cytosolic GSH is as high as $10 \mathrm{mM}$, while GSSG in the cytosol is as low as nanomolar concentration. The redox potential of $\mathrm{E}_{\mathrm{GSH}}$ in the cytosol is about $320 \mathrm{mV}$ 


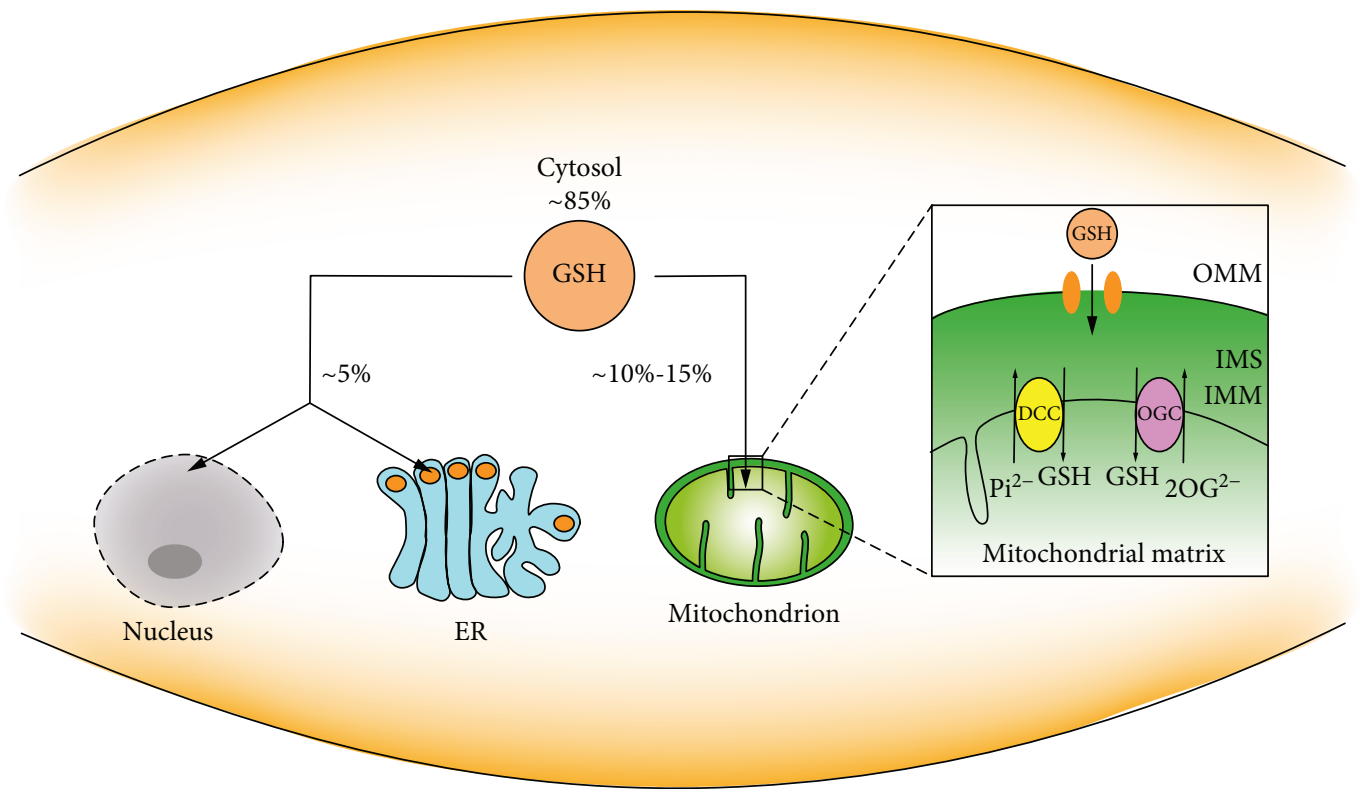

FIGURE 2: Distribution of intracellular GSH. GSH is distributed in the cytosol, nucleus, mitochondria, and ER.

[20]. The highly reduced GSH pool has also been found in a variety of species $[21,22]$. The cytosol contains the largest GSH pool, which does not contradict its distribution of GSH in other subcellular organelles. Due to the lack of GS in subcellular compartmentation, GSH must be imported into the subcellular organelles from the cytosol.

2.2.2. Mitochondrial GSH. Mitochondria are coated by two membranes and separated into two spaces, the matrix surrounded by the inner mitochondrial membrane (IMM) and the intermembrane space (IMS) between the IMM and the outer mitochondrial membrane (OMM). Although the enzymes in these two separate chambers, the IMS and matrix, are not identical, each is providing NADPH and exchanging molecules through its mechanism. Mitochondria are the main sites for aerobic respiration and producing ROS, mainly $\mathrm{O}_{2}{ }^{-}$. Mn-dependent superoxide dismutase (MnSOD) reduces $\mathrm{O}_{2}{ }^{-\cdot}$ to $\mathrm{H}_{2} \mathrm{O}_{2}$, and the gradual accumulation of $\mathrm{H}_{2} \mathrm{O}_{2}$ further generates free radicals. In the mitochondria, catalase reduces $\mathrm{H}_{2} \mathrm{O}_{2}$ to $\mathrm{H}_{2} \mathrm{O}$ and $\mathrm{O}_{2}$ but due to the low catalase content, a certain amount of GSH is required to maintain the redox balance. During the oxidation of GSH to GSSG by glutathione peroxidase (GPX), $\mathrm{H}_{2} \mathrm{O}_{2}$ is reduced to $\mathrm{H}_{2} \mathrm{O}$, which can offset the $\mathrm{H}_{2} \mathrm{O}_{2}$ produced by MnSOD $[23,24]$.

The mitochondrial glutathione (mGSH) pool only accounts for $10 \% \sim 15 \%$ of the total glutathione pool, and the internal glutathione is mainly present in a reduced state $[25,26]$. Considering the mitochondrial volume, the concentration of mGSH per mitochondria is similar to that of cytosolic GSH and there is no concentration gradient in the mitochondrial inner membrane space. Mitochondria are not able to synthesize GSH as for lacking GS, but they can take up GSH from the cytosol [23]. GSH in the cytosol passes through the two layers of the OMM and IMM to reach the destination in the mitochondria. The monotonous uptake of GSH through the OMM is facilitated by the pore proteins, which allow molecules less than $\sim 5 \mathrm{kDa}$ to freely pass [27]. The concentration of small molecules in the IMS is equivalent to the concentration in the outer cytoplasm. Small molecules entering the IMS cannot penetrate into the mitochondrial matrix because of the different lipid composition between the IMM and OMM [28-30]. Since GSH exists in an anionic form at physiological $\mathrm{pH}$ [31], the task of GSH entering the mitochondrial matrix is borne by the two anion transporters localized on the IMM, dicarboxylate carrier (DCC), and 2-oxoglutarate carrier (OGC) [32]. DCC exchanges inorganic phosphate, $\mathrm{Pi}^{2}$-, or OGC exchanges 2-oxoglutarate $\left(2-\mathrm{OG}^{2-}\right)$ when GSH enters the matrix [33]. These specialties in the IMM make it possible for GSH to transport into the mitochondria. Thus far, the exact mechanism of GSH transporting in mitochondria needs further verification.

2.2.3. Nucleus GSH. In spite of the minimal GSH concentration in the nucleus, studies have confirmed the important role of nuclear GSH in the cell cycle $[16,34,35]$. Cells that are ready for division have higher levels of nuclear GSH $[13,36]$. Although there is no definitive proof for this mechanism, it cannot neglect the fact that GSH accumulates in the nucleus at an early stage of cell growth, and when the cells reach confluence, it is reuniformly distributed between the nucleus and the cytosol [34]. The study concerning the correlation between GSH and cell cycle may be helpful for us to better understand cell physiology and cellular metabolic processes.

Lower and medium levels of ROS are generally recognized as inducing mitosis and having beneficial effects in cell growth, while excessive ROS can cause DNA strand breaks, DNA mutations, and DNA double-strand aberrations, further leading to oxidative stress. The sulfhydryl group in GSH is essential in maintaining the status of DNA repair and expression in the nucleus [37]. In the process of 


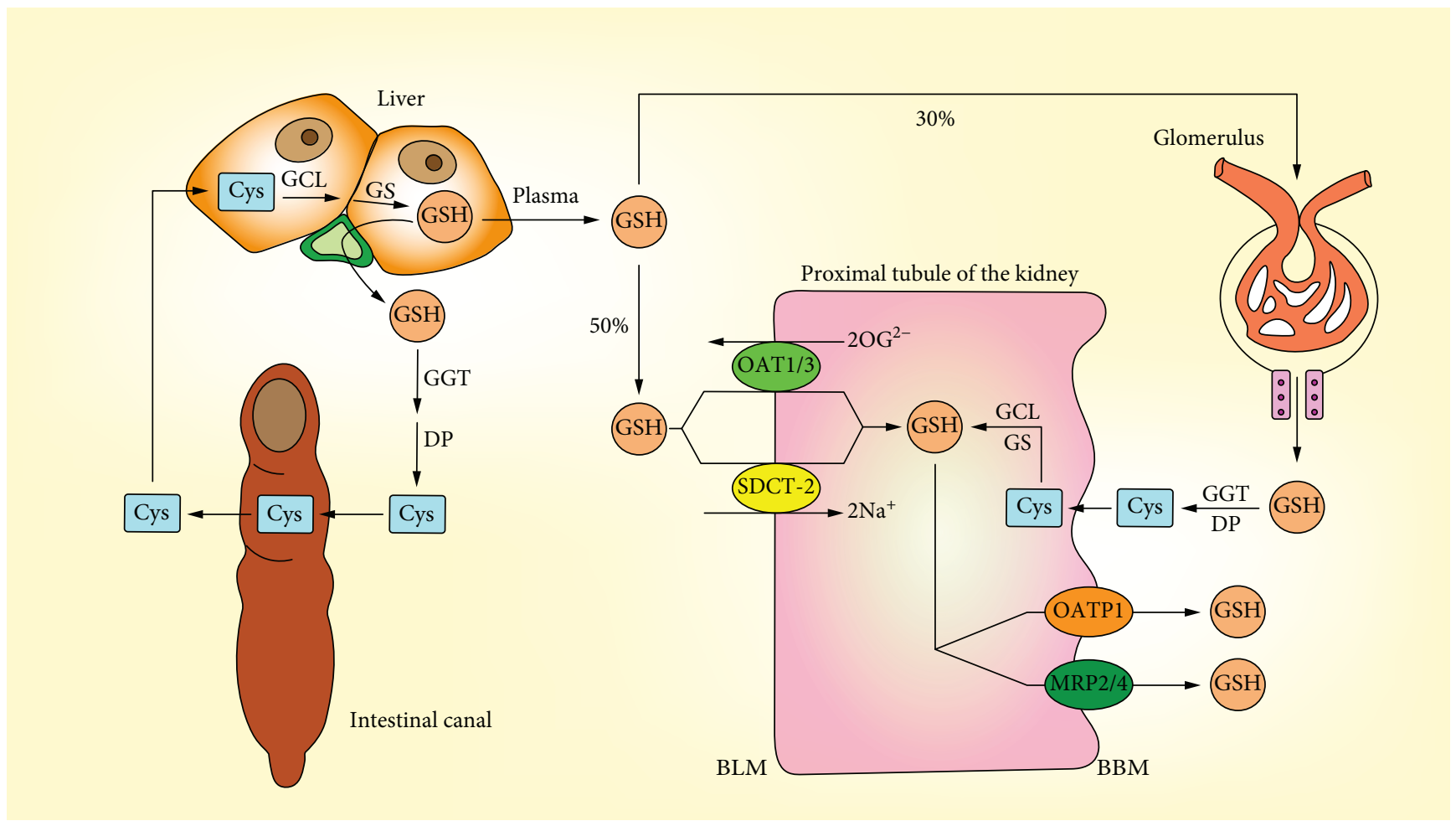

Figure 3: Transport of GSH. The liver is the main source of GSH, the kidney is the main organ that ingests and degrades GSH, and the small intestine participates in the GSH enterohepatic circulation. The renal proximal tubule is the place where the whole process of GSH transport, synthesis, and degradation is completed.

ribonucleic acid reduction, GSH acting as a donor of hydrogen catalyzes the reduction of ribonucleic acid to deoxyribonucleic acid, which plays a contributory role in DNA synthesis [38].

2.2.4. ER GSH. ER is interlaced in the cytoplasm and performs a variety of functions, including protein biosynthesis, folding, translocation, and glycosylation and formation of disulfide bonds [39]. The formation of disulfide bonds is the key process for the protein synthesis in ER and also benefits this highly oxidative environment. Accumulation of unfolded or misfolded proteins results in ER stress. The ER glutathione seems to be a special case where the oxidized form accounts for the most. The ratio of GSH: GSSG in ER is as high as 1 15:1 [40]. A highly oxidizing environment is a necessary condition for ER to perform its function [41]. Changes in the redox state of ER significantly affect the formation of disulfide bonds in which in this process, GSH is oxidized to GSSG.

2.3. GSH Transport. GSH in tissues is mainly derived from hepatocytes, which can only be synthesized in hepatocytes and cannot be degraded. Part of GSH is discharged to the blood through the transport proteins of the hepatocytes, and the other part is discharged to the bile through the bile duct $[42,43]$.

In mammalian tissues, the kidney is the main organ that takes up plasma GSH. $80 \%$ of GSH in the plasma is absorbed by the kidney, and $3 / 8$ of them are rapidly decomposed by $\gamma$-glutamyltransferase (GGT) and dipeptidase (DP) which are located in the brush border membrane (BBM) of the renal tubule after glomerular filtration, and the amino acids absorbed by the renal cells are used to resynthesize proteins or GSH. In addition, the other 5/8 of GSH enters the renal tubule and is absorbed by the specific transporter on the basolateral plasma membrane (BLM) in the form of intact tripeptide [42, 44] (Figure 3). There are two main transporters that facilitate BLM to ingest GSH through a nonfiltering mechanism, and the difference between them is that whether or not they rely on $\mathrm{Na}^{+}$[31]. Organic anion transporter 1 (OAT1) and OAT3 can absorb GSH through exchanging 2-oxoglutarate (2OG). Probenecid and p-aminohippurate $(\mathrm{PAH})$ are two classical inhibitors of OATs that significantly inhibit GSH uptake [45]. Dimethyl succinate (DMS) is a substrate of sodium-dicarboxylate 2 (SDCT2) which significantly inhibits the absorption of GSH by isolated proximal tubule cells [46]. The stoichiometry of $\mathrm{Na}^{+}$-GSH cotransportation indicates that at least two $\mathrm{Na}^{+}$ couplings are required for absorption per GSH molecule during transport through the SDOT-2 carrier [31].

The process of the GSH outflow in BBM is important for the overall GSH transport. Through the study on the vesicles isolated from the rat kidney cortex, it can be concluded that GSH transport in BBM is a process that is dependent on membrane potential. Unlike GSH transport through BLM, ion coupling is not involved in GSH transport through BBM [47]. Although there is still no evidence to prove the exact vectors that play the direct role in the GSH transport 


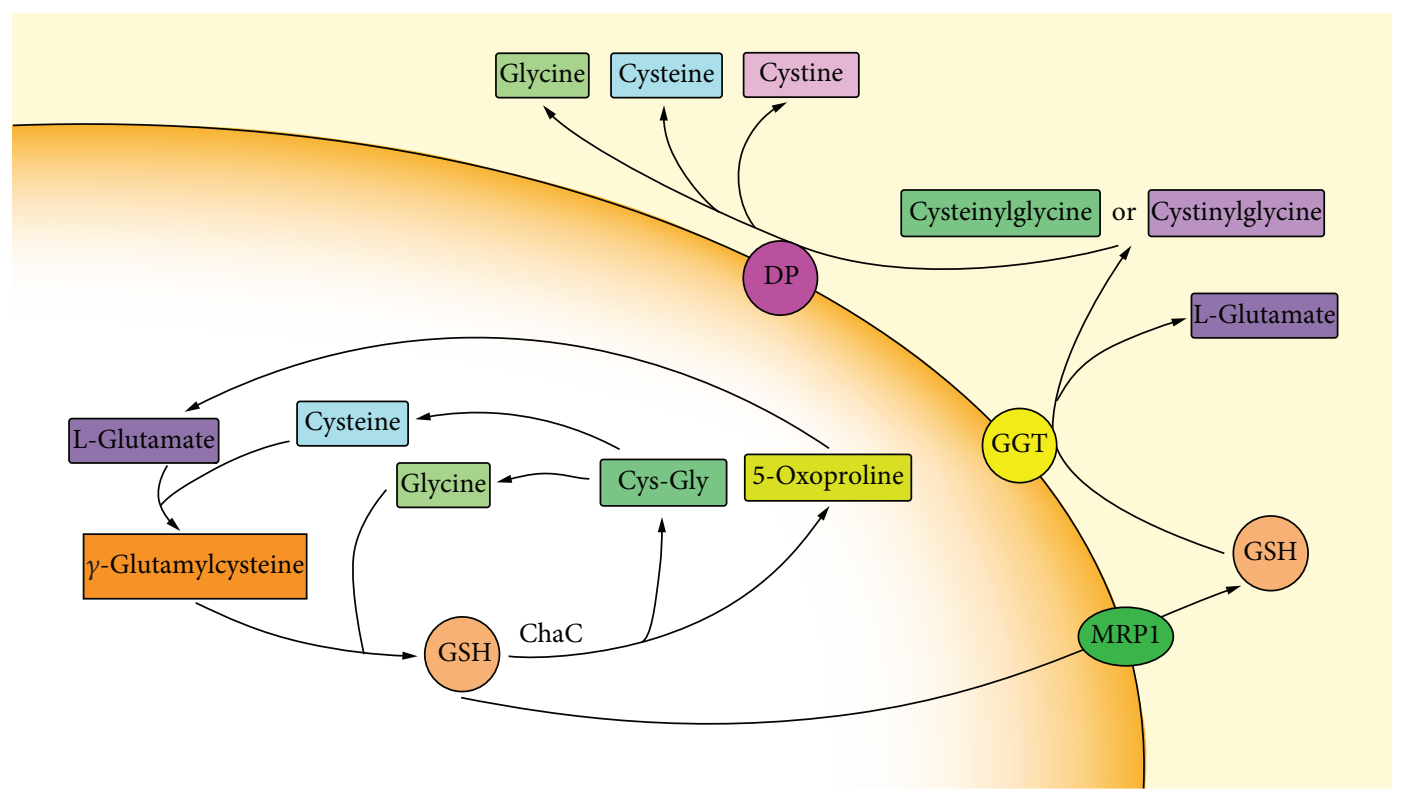

FIGURE 4: Two degradation pathways of GSH. One way occurs outside the cell where GSH is degraded by $\gamma$-glutamyltransferase (GGT) which is expressed only on the outer surface of particular cell; the other newly discovered pathway occurs in the cytoplasm where GSH is degraded through $\mathrm{ChaC} 1$ and ChaC2.

through BBM, it can lead to assumptions based on existing knowledge. There are two types of transporters that contribute to GSH transport [48]. One of the currently more convincing vectors is the organic anion-transporting polypeptide 1 (OATP1), which is expressed in the sinusoidal membrane and demonstrated to transport GSH [49]. Another type of vector that may play a role in the GSH efflux process is multidrug resistance proteins (MRPs) [50]. GSH excreted to the bile is hydrolyzed by GGT and DP on the surface of bile duct epithelial cells or small intestinal epithelial cells. The cysteine produced by hydrolysis can be reused by the small intestine to synthesize GSH and participate in the enterohepatic circulation.

2.4. GSH Metabolism. The structure of GSH is unique in the condensation of glutamate and cysteine producing a $\gamma$-carboxyl group rather than the usual $\alpha$-carboxyl group. Most enzymes cannot hydrolyze $\gamma$-carboxyl groups. GGT is the only enzyme expressed on a specific cell surface that is capable of hydrolyzing this particular group [51]. GSH transported by the cell reaches to the GGT active site and is degraded to L-glutamate and cysteinylglycine or cystinylglycine and is then released as glutamate, cysteine, cystine, and glycine under the catalysis of DP. These single amino acids or dipeptides are taken up by the cells to complete the synthesis of GSH (Figure 4).

New pathways for GSH metabolism have also been discovered in recent years. Unlike GGT, the newly discovered ChaC family can enzymatically degrade GSH localized to the cytoplasm [52, 53]. ChaC1 is discovered in bacterial BtrG proteins and mammalian $\gamma$-GCT proteins, which hydrolyze GSH to produce cysteinyl-free Cys-Gly and 5-oxoproline [54]. It is worth noting that ChaC1 only works on reduced GSH. ChaC2 is another member of the ChaC family, which is found in E. coli, yeast, and humans. Its specificity for
GSH is similar to that of ChaC1, producing 5-oxoproline and Cys-Gly. Enzyme kinetic studies showed that the catalytic activity of the two was significantly different. The efficiency of the ChaC2 enzyme in degrading GSH was $1 / 20 \sim 1 / 10$ times higher compared to that of the ChaC1 enzyme [55]. GSH metabolism plays a key role in maintaining GSH homeostasis, nutrient recycling and recovery, and signal transduction.

\section{Antioxidant Role of Cellular GSH}

ROS is a product of normal cellular metabolism and involved in physiological and biochemical processes. Therefore, balancing the generation and elimination of ROS to maintain the favorable physiological and suitable environment is of great importance [56]. Oxidative stress is caused when the normal oxidation/antioxidant equilibrium state is destroyed. In general, cells are able to cope with mild oxidative stress, while the severe oxidative stress beyond the cell antioxidant capacity can cause damage to lipids, proteins, and DNA, even leading to cell death. There are two main possible strategies to inducing oxidative stress: one is to directly increase the level of ROS and the other is to impair the antioxidant defense system. The GSH system is one of the important antioxidant defense lines against ROS (Figure 5).

Maintenance of cellular redox balance is essential for cell fate. The cellular redox state is often referred to the balance of $\mathrm{NAD}^{+} / \mathrm{NADH}, \mathrm{NADP}^{+} / \mathrm{NADPH}$, and GSH/GSSG [57]. Among those redox-balancing partners, the two forms of glutathione can be interconverted by enzyme catalysis. Under normal physiological conditions, the vast majority of glutathione is the reduced form. Mitochondria are sites of cellular oxidative respiration, in which ROS are produced by enzymatic or nonenzymatic reactions [58]. Although 


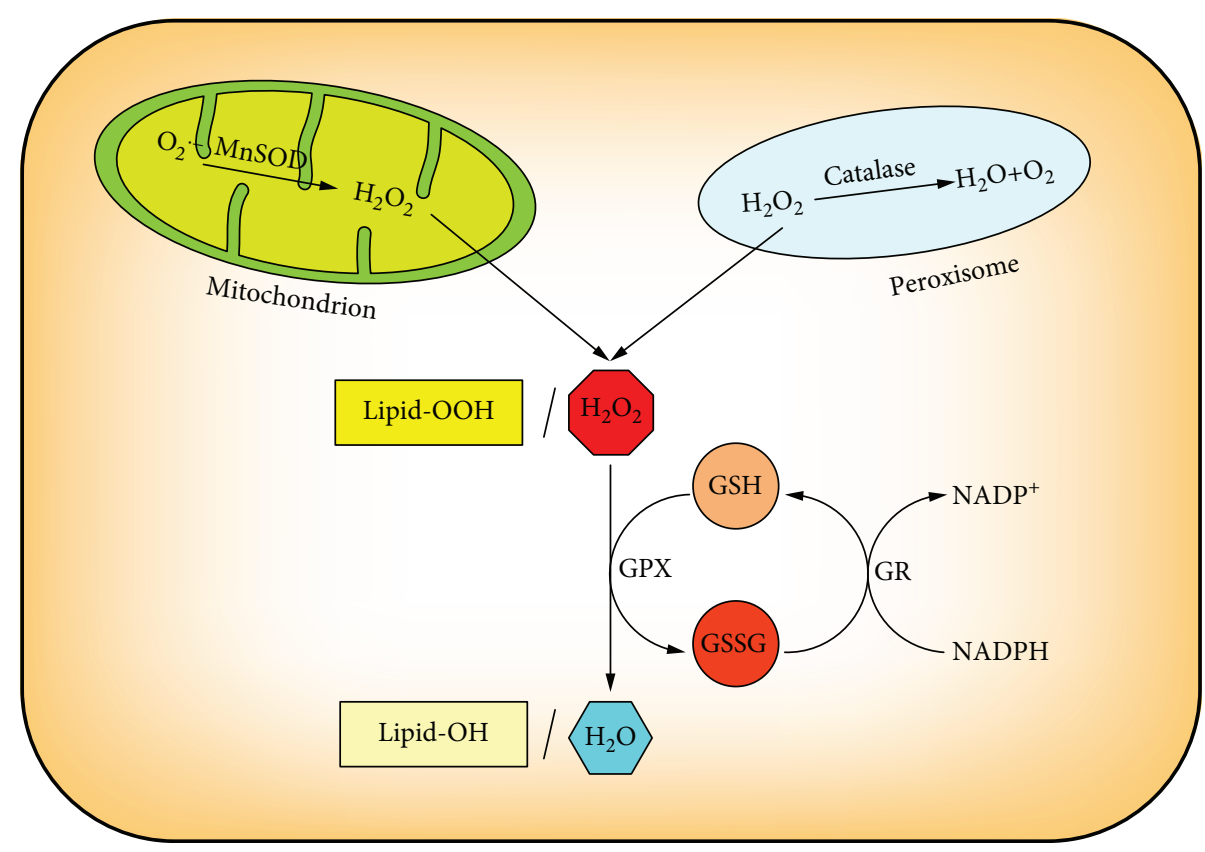

FIgURE 5: The antioxidant role of cellular GSH. Glutathione peroxidase (GPX) converts $\mathrm{H}_{2} \mathrm{O}_{2}$ and Lipid-OOH to $\mathrm{H}_{2} \mathrm{O}$ and Lipid-OH where GSH is oxidized to GSSG, and glutathione reductase (GR) reduced GSSG to GSH dependent on NADPH, thereby forming a redox cycle to prevent oxidative damage.

mGSH accounts for only $10 \% \sim 15 \%$ of the total GSH, its role as an antioxidant cannot be ignored. $\mathrm{H}_{2} \mathrm{O}_{2}$ is a product of aerobic metabolism and is primarily reduced by glutathione peroxidase (GPX) in which in this process, GSH is oxidized to GSSG. GPX is an important peroxide-degrading enzyme. It can catalyze the conversion of GSH to GSSG, reduce toxic peroxides to nontoxic hydroxyl compounds, and promote the decomposition of $\mathrm{H}_{2} \mathrm{O}_{2}$, thereby protecting the structure and function of cell membranes from peroxide interference and damage. GSSG is then reduced to GSH by glutathione reductase (GR) which is associated with NADPH which is oxidized to $\mathrm{NADP}^{+}$, thereby forming a redox cycle to prevent oxidative damage [20]. At the same time, GPX reduces lipid peroxides (Lipid-OOH) to nontoxic lipid alcohols (Lipid-OH) with GSH as a substrate. This cycle of mutual transformation enables the continuous elimination of free radicals in the cells [7].

\section{Role of GSH in Programmed Cell Death}

Cancer cells exhibit a higher ROS level and also develop a greater GSH antioxidant system in order to avoid causing oxidative stress. Programmed cell death, including apoptosis, autophagy, necroptosis, and ferroptosis, is initiated by serials of intracellular programs [59]. In some cases, GSH depletion not only triggers one form of programmed cell death but also may initiate multiple forms of cell death. These different forms of cell death may be simultaneously or successively initiated and then interact with each other, and finally, one cell death form may mainly exist [60].

4.1. GSH and Apoptosis. Apoptosis is the most recognized form of programmed cell death which is initiated and executed by the caspase family. It is a genetically controlled and actively cascading cell death process that is characterized by membrane shrinkage, chromatin condensation, and formation of apoptotic bodies [61]. Studies have shown that the GSH/GSSG redox status is an important indicator of apoptosis in cancer cells. Apoptosis is consistently associated with a reduction in the GSH/GSSG ratio [62]. The decrease in GSH impairs the antioxidant system and leads to the increase in ROS generation which accelerates mitochondrial damage and induces apoptosis (Figure 6).

Intracellular GSH loss precedes the destruction of mitochondrial integrity, cytochrome $c$ release, and caspase activation and is recognized as an early event in the progression of apoptosis in response to different stimuli. GSH depletion occurs in both intrinsic apoptosis and extrinsic apoptosis $[63,64]$. A decline in GSH induced ROS generation and the release of cytochrome $c$, following depletion of the mitochondrial GSH level and caspase 3 activation [65]. Cellular GSH exported into the extracellular space is also demonstrated in the initiation of apoptotic signaling or promotion of apoptotic progression [66]. Cancer cells undergoing apoptosis release a large amount of intracellular GSH into the extracellular environment [67]. Reducing GSH efflux in the apoptotic process could attenuate cell death. Contrarily, stimulation of GSH synthesis could efficiently protect mitochondrial membrane potential loss and inhibit apoptosis [68]. In addition, the exogenous supply with $\mathrm{N}$-acetyl-Lcysteine (NAC) restores the cellular GSH level and prevents the GSH depletion-induced apoptosis [69].

The elevated level of ROS and mGSH/GSSG imbalance can stimulate the intrinsic apoptosis pathway. Impairment of GSH uptake to the mitochondria directly affects the mitochondrial function. Depletion of mGSH leads to the 


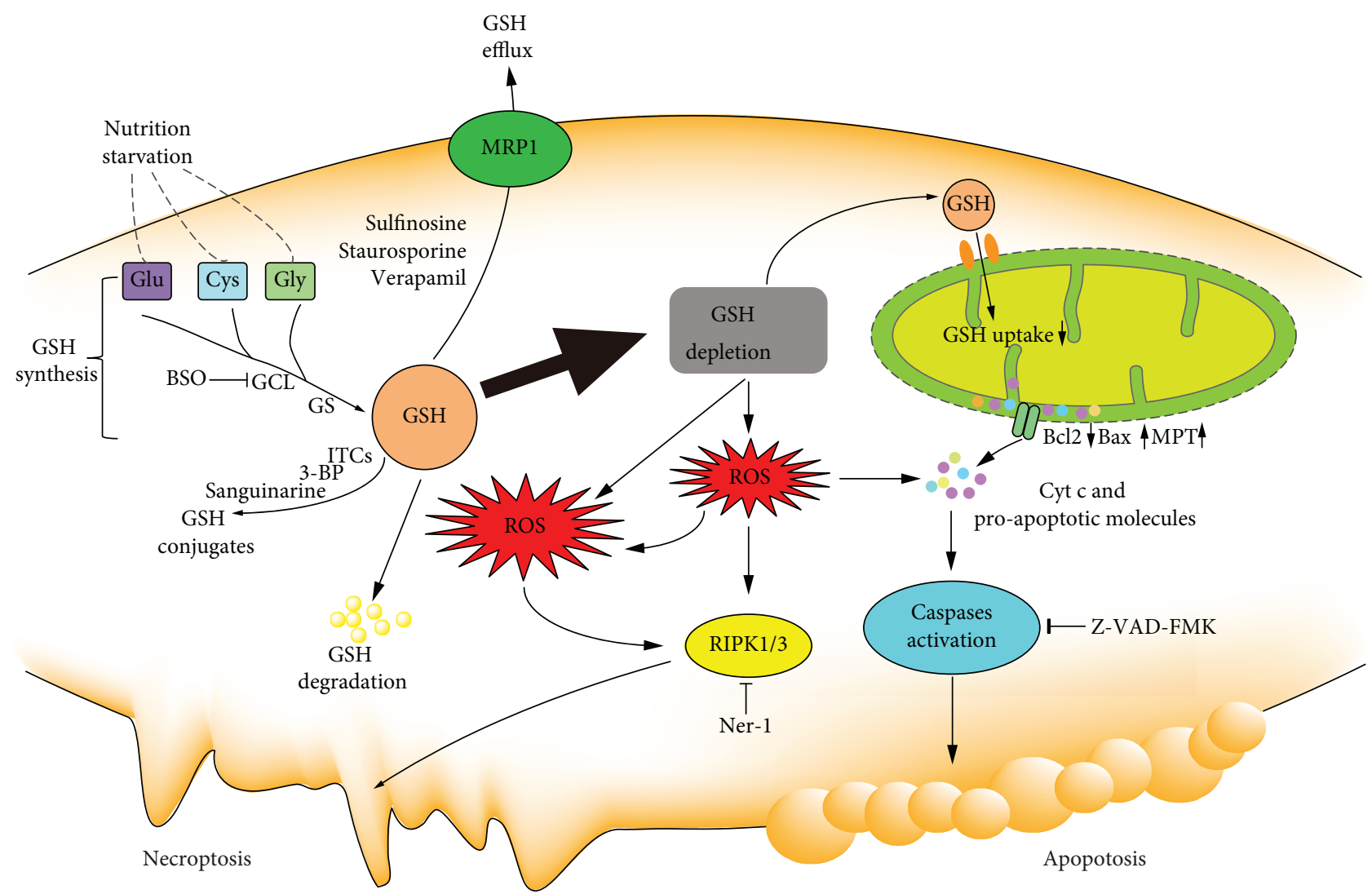

FIGURE 6: The role of cellular GSH in apoptosis and necroptosis. GSH depletion through nutrition starvation or GSH synthesis inhibition or conjugation with GSH or GSH efflux or GSH degradation induces ROS generation which results in the occurrence of proapoptotic signals, such as the disruption of MMP, increased bax, decreased bcl2, cytochrome c release, and caspase activation. Excess ROS accumulation induces necroptosis.

instability of the mitochondrial structure and release of proapoptotic proteins from the outer mitochondrial membrane [70]. The stimuli cause mitochondrial membrane permeabilization through mitochondrial permeability transition (MPT) opening or pores formed by bax and bcl2, resulting in apoptosis-inducing factor release, apoptosome complex formation, and caspase activation [71-73].

4.2. GSH and Necroptosis. Although necrosis is originally thought to be a passive and unregulated form of cell death, studies have shown that some form of necrosis can be regulated by intracellular proteins, which is also termed as necroptosis $[74,75]$. Necroptosis is an alternative form of programmed cell death with distinct characters in the mitochondria, lysosome, and plasma membrane, exhibiting a translucent cytoplasm, swelling organelles, increased cell volumes, and disruption of the plasma membrane [76, 77]. Necroptosis could be initiated in a way that is similar to extrinsic apoptosis. Receptor-interacting protein kinases 1 (RIPK1) and 3 (RIPK3) are two key regulators involved in the execution of necroptosis. GSH depletion by pharmacological inhibition causes oxidative stress-induced necroptosis [78]. Necrostatin-1, an inhibitor of RIPK1, can protect cell from GSH depletion inducing cell death in HT-22 cells through inhibition on GCL [79]. Artesunate triggers necroptosis by decreasing the GSH/GSSG ratio and increasing ROS generation in human renal carcinoma cells which can be reduced by necrostatin-1 or knockdown of RIPK1 [80]. To our knowledge, an excess level of ROS induces apoptosis, while massive ROS may lead to necroptosis. GSH depletion-induced ROS generation can simultaneously induce apoptosis and necrosis in cancer cells in some cases (Figure 6). Dimethyl fumarate (DMF) induced typical features of necroptosis-like excessive autophagy, disintegration of mitochondrial membrane potential, LDH release, and accumulation of ROS in colon cancer cells by depleting the cellular GSH level [81]. GSH depletion by cystine starvation or the GSH degradation results in oxidative stress which leads to necroptosis and ferroptosis by directly oxidizing lipids [82].

4.3. GSH and Ferroptosis. Ferroptosis, a kind of programmed cell death, is morphologically, biochemically, and genetically different from other well-known forms of cell death [83]. The characterized features of ferroptosis are iron dependent, GPX4 inactivation, and lipid ROS accumulation [84]. Ferroptosis can be induced by small molecules or GSH biosynthesis inhibitions or GPX4 impairment or some physiological conditions [85] (Figure 7). Cysteine starvation and further GSH depletion cooperate to elevate lipid ROS. Cystine deprivation induced GSH efflux and extracellular degradation for balancing the intracellular cysteine level 


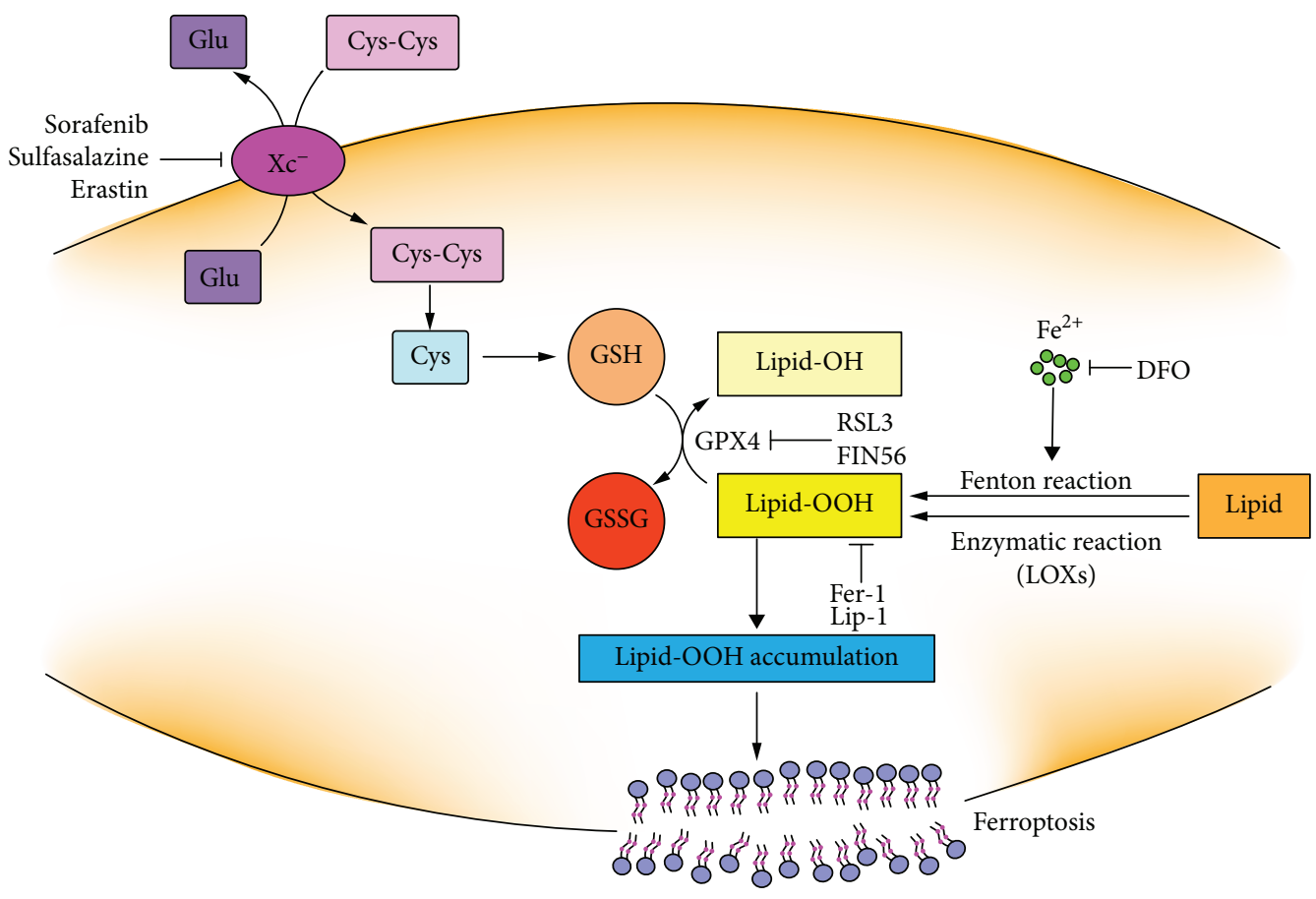

FIGURE 7: The mechanism of GSH depletion in induction of ferroptosis. Lipid-OOHs can be formed by autoxidation via Fenton reaction or by enzymatic reaction via lipoxygenases (LOXs). Lipid-OOHs are regulated by the balance between the activities of GPX4 and LOXs or Fenton reaction. System $\mathrm{X}_{c}{ }^{-}$impairment or GPX4 inactivation leads to Lipid-OOH accumulation which cannot be effectively cleared under the loss of GPX4 activity. Ultimately, the accumulation of Lipid-OOH triggers ferroptosis. Ferroptosis can be inhibited by DFO, liproxstatin-1 (Lip-1), and ferrostatin-1 (Fer-1).

[86]. GSH depletion through inhibition on cystine uptake is essential for erastin-induced ferroptosis. Additionally, the knockout of GCL could sensitize cells to ferroptosis induced by cysteine starvation [87]. Erastin treatment impairs the antioxidant defenses of the cell by indirectly inactivating GPX4 activity resulting in the increase in the cytoplasmic ROS and lipid ROS accumulation.

GPX4 can convert Lipid-OOH to nontoxic Lipid-OH. GPX4 reduced Lipid-OOH using GSH as a cosubstrate. Pharmacological inhibition or genetical depletion of GPX4 promotes lipid ROS generation or, what is more, is lethal, while upregulation of GPX4 can diminish lipid ROS [88-90]. Lipid-OOH formation and membrane damage are sufficient inducers in ferroptosis [91]. RSL3 is identified as a small molecule that enhances the lethality toward oncogene-harboring cancer cells by increasing oxidative stress through altering the iron regulatory proteins and genes [92]. Afterwards, RSL3 is proved to be a ferroptosis inducer by covalently targeting the active site of selenocysteine of GPX4 and resulting in the accumulation of lipid ROS. But the mechanism of RSL3-induced ferroptosis is not by depleting GSH but by inactivating GPX4. GPX4 silence sensitizes cells to RSL3-induced ferroptosis which is accompanied by lipid ROS accumulation [93]. Consequently, direct inactivation of GPX4 can also induce ferroptotic cell death even when cellular cysteine and GSH levels are normal. FIN 56 is a special inducer of ferroptosis that can cause a slower accumulation of ROS as for the downregulation of GPX4 protein abundance [94]. Together, all these types of small molecules can induce ferroptosis by different modulatory profiles, while ultimately, all of them cause the loss of GPX4 activity and generation of lipid ROS. Therefore, it can conclude that GPX4 is the key regulator of ferroptosis and the GSH antioxidant system plays a central role in the regulation of ferroptosis $[90,95]$.

Ferroptotic oxidative signals are mainly produced by iron-mediated Fenton reaction or enzymatic reaction via lipoxygenases (LOXs) or when the GSH antioxidant system is impaired $[96,97]$. GSH deficiency or GPX4 inactivation in inducing ferroptosis involves the enhanced production of oxygenated phosphatidylethanolamine (PE) species [98]. Suppression on the formation of oxygenated PE species can inhibit ferroptosis [99]. Depletion of GSH through the inhibiting system $\mathrm{X}_{\mathrm{c}}{ }^{-}$induces ferroptosis that could be prevented by liproxstatin-1 (Lip-1), ferrostatin-1 (Fer-1), and iron chelator deferoxamine (DFO) $[83,100,101]$.

4.4. GSH and Autophagy. Autophagy is a catabolic process by degrading cytoplasmic constituents or impaired organelles in autolysosomes for recycling under stress condition. Autophagy has long been considered a cell protective mechanism, while excessive autophagy can also trigger cell death and be regarded as a tumor suppressive mechanism [102, 103].

Growing evidence supports the role of ROS in the regulation of autophagy, but evidence about the mechanism and interplay between GSH and the initiation and promotion of autophagy is still elusive [104]. GSH, one of the principal molecules in the thiol network, has been indicated as the suspect for induction of autophagy [105]. The low level of GSH acts as a signal to activate autophagy as an adaptive 


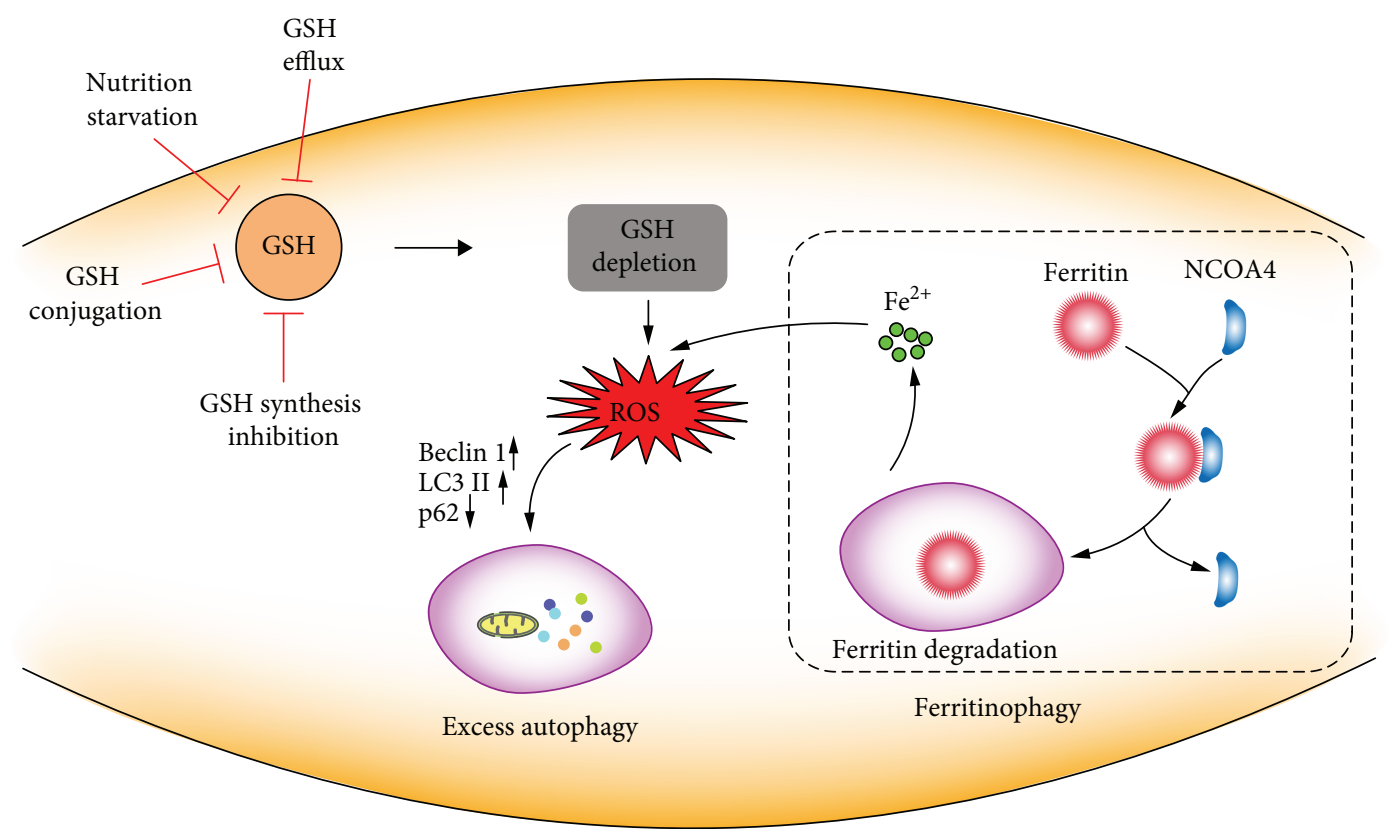

FIGURE 8: The role of cellular GSH in autophagy. GSH depletion through nutrition starvation or GSH synthesis inhibition or conjugation with GSH or GSH efflux induces ROS generation. ROS accumulation promotes changes in autophagy-related proteins, such as LC3 I/II conversion, p62 degradation, and autophagic vacuole formation. Additionally, ROS induce NCOA4-mediated ferritin degradation in an autophagy process, called ferritinophagy, which is promoting free iron release and accelerating ROS generation.

stress response [106, 107]. The ways that modulate the intracellular GSH state can drive autophagic response at multiple levels (Figure 8). The dysfunction of system $\mathrm{X}_{\mathrm{c}}{ }^{-}$by pharmacologic inhibition (sulfasalazine) causes GSH decrease and ROS generation and triggers autophagic cell death [108]. Nutrition starvation can result in the modulation of the cellular GSH content which is mediated by GSH extrusion, GCL inhibition, and the formation of GS-R [109]. Under the GSH depletion case, $\mathrm{H}_{2} \mathrm{O}_{2}$ induced autophagic cell death with increased LC3 conversation and p62 degradation and enhanced autophagic vacuole formation [110]. Together, the decreased cellular GSH level contributes to autophagy and affects the autophagic process. Overall, the possible relationship between GSH and autophagy still deserves to be further investigated.

Ferroptosis is a form of cell death that is dependent on the induction of the autophagic process via a form of cargospecific autophagy known as ferritinophagy [111]. Autophagy plays a decisive role in the degradation of cytosolic proteins. The impaired autophagic process can induce protein accumulation [112]. The proper function of lysosomes plays an essential role in ferroptotic cell death [113]. The activity of lysosomes is increased in ferroptosis in order to enhance chaperone-mediated autophagy to degrade GPX4 [114]. Inhibition of lysosomal function by bafilomycin A1 (BalfA1) and chloroquine (CQ) can significantly delay the ferroptosis process induced by erastin [115]. Autophagy flux is associated with ferroptosis for promoting the turnover of ferritin in erastin-treated cancer cells [116]. Ferritin degradation is dependent on autophagy where nuclear receptor coactivator 4 (NCOA4) acts as a cargo receptor targeting ferritin to autophagosome [117-119]. Dihydroartemisinin
(DHA) induced ferroptosis in acute myeloid leukemia cells through activating the autophagy process with decreased GSH, ferritin degradation, and labile iron accumulation [120]. The exact mechanism of the connection between autophagy and ferroptosis still remains largely unknown.

\section{GSH Depletion as a Means of Cancer Therapy}

A relationship between the increased GSH level and resistance to chemotherapies was observed in many cancers [121]. Impairment in the GSH antioxidant defense system could sensitize cancer cells to current chemotherapeutics. It suggested that the moderate decline in the GSH level would be an effective strategy to improve the sensitivity of cancer cells to chemotherapies. Therefore, depletion of cellular GSH in cancer cells will make them more susceptible and sensitive to oxidative stress and chemotherapies. Cysteine insufficiency or glutamate sufficiency or pharmacological and genetic inhibition of system $\mathrm{X}_{\mathrm{c}}{ }^{-}$can reduce the resistance of cancer cells to chemotherapies [122]. GSH depletion promotes cancer cell undergoing different forms of programmed cell death, such as apoptosis, necroptosis, autophagy, and ferroptosis. Ways for depleting the cellular GSH level to induce oxidative stress include the following: creation of the source shortage for GSH synthesis, inhibition of the GSH synthesis process, direct conjugation with GSH, and promotion of cellular GSH efflux [123-126].

5.1. Inhibition on System $\mathrm{X}_{c}^{-}$. Cysteine is the main source for protein synthesis. Undoubtedly, it is of critical importance for maintaining the GSH level. Cysteine typically presents in its oxidized form in the extracellular space and can be 
taken up into the intracellular space via a system $\mathrm{X}_{\mathrm{c}}{ }^{-}$antiporter. System $\mathrm{X}_{\mathrm{c}}{ }^{-}$, consisting of SLC3A2 (4F2, solute carrier family 3, membrane 2) and SLC7A11 (xCT, solute carrier family 7, membrane 11), forms as a glutamate/cysteine antiporter in the cell membrane [127]. $\mathrm{xCT}$ is the light chain of system $\mathrm{X}_{\mathrm{c}}{ }^{-}$. Elevated expression of xCT has been demonstrated in many types of cancer and is related to chemoresistance and poor prognosis in cancer patients [128-133].

A reduction in the uptake of extracellular cysteine can directly cause intracellular GSH depletion. Inhibition on $\mathrm{xCT}$ expression triggers cysteine starvation and subsequently induces cell growth arrest in cancer cells. Stabilization of xCT promotes the uptake of cysteine for GSH synthesis and protects cancer cells from high levels of ROS [134]. Therefore, regulation of $\mathrm{xCT}$ is considered a promising therapeutic target for cancer therapy [135]. Pharmacological inhibition of system $\mathrm{X}_{\mathrm{c}}{ }^{-}$inhibits cancer cells in vitro and delays tumor growth in vivo. Disruption on $\mathrm{xCT}$ function inhibits cell invasion and tumor metastasis [136]. The inhibitory effects on cancer cells can be ascribed for the rapid depletion of GSH by xCT dysfunction and subsequently increase in ROS generation.

Erastin is an inhibitor of system $\mathrm{X}_{\mathrm{c}}{ }^{-}$that can lead to the depletion of GSH [83]. GSH-depleting effects of erastin could be reversed by supplying with GSH and N-acetylcysteine (NAC). Imidazole ketone erastin (IKE), a carbonyl erastin analogue, also exhibits system $\mathrm{X}_{\mathrm{c}}{ }^{-}$inhibition activity and displays more potency to selective lethality to cancer cells than erastin [137]. Sorafenib promotes ferroptosis in HCC cells by its ability to inhibit system $\mathrm{X}_{\mathrm{c}}{ }^{-}$and deplete GSH [101]. Sorafenib can also potentiate cisplatin cytotoxicity in resistant head and neck cancer cells through the inhibitory effect on xCT [138]. Sulfasalazine is an anti-inflammatory drug which can be used for the treatment of inflammatory bowel disease and rheumatoid arthritis and is also proved to be a potent inhibitor of system $\mathrm{X}_{\mathrm{c}}{ }^{-}$. It can sensitize cancer cells not only to chemotherapies but also to radiotherapies [139-141]. Pseudolaric acid B, a natural diterpene acid isolated from the root and bark of Pseudolarix kaempferi, can trigger ferroptosis in glioma cells by depleting cellular GSH through inhibition of xCT $[142,143]$.

5.2. Inhibition on GCL. $\gamma$-GCL plays a key role in the synthesis and maintenance of the cellular GSH level. It is the first and rate-limiting enzyme in GSH synthesis consisting of the GCLC catalytic subunit and GCLM modifier subunit [144]. Overexpression of GCL increases the cellular GSH level, and cells exhibit more resistance to oxidative stress [145]. Adrenomedullin induces the expression of GCLC and protects cells against oxidative stress [146]. On the contrary, knockdown of GCLC could elevate the cellular ROS level [147]. L-Buthionine-(S,R)-sulfoximine (BSO) is an inhibitor of $\gamma$-GCL. It has been shown to increase the efficacy of nifurtimox against cancer cells and be an effective modulator of GSH-mediated chemoresistance by increasing the in vitro cytotoxicity of alkylating agents and radiation [148].

5.3. Conjugation with GSH. The most direct strategy to deprive GSH is to react with it. Some natural molecules exhibit good affinity to GSH. Sanguinarine directly reacts with cellular GSH and causes a rapid and sever depletion of GSH. It results in the subsequent modification of the membrane integrity and relates to a promotion of apoptotic response dependent on caspase 3 and caspase 7 activation in PC3 human prostatic adenocarcinoma cells [149]. 3-Bromopyruvate (3-BP), an alkylating agent, has high reactivity toward thiols and rapidly conjugates with GSH in the cell-free system and many cell types $[150,151]$. It has been proved to have antitumor activities [152, 153]. Isothiocyanates (ITCs) are natural phytochemicals abundantly existing in cruciferous vegetables. The central carbon of the ITCs is highly electrophilic and can react with thiols. At physiological $\mathrm{pH}$, ITCs react predominantly with the sulfhydryl group of cysteine residues in GSH. Accumulative evidence has proved that ITCs, such as sulforaphane (SFN), phenethyl isothiocyanate (PEITC), and ally isothiocyanate (AITC), are highly effective in chemoprevention and have antitumor activities in vitro and in vivo [154-158]. PEITC exhibits potential ability against not only solid tumor but also leukemia cells through the rapid deprive of mitochondrial GSH and elevation of ROS [70, 159].

5.4. Enhancement of GSH Efflux. The development of the multidrug resistance (MDR) phenotype poses as a major clinical problem that limits the curative potential of anticancer drugs. The characterized phenotype of MDR is the typically increased expressions of P-glycoprotein (P-gp) and MRPs. P-gp and MRPs can extrude anticancer agents out of cell consuming ATP and result in the chemotherapy failure. Inhibition of MRPs could reduce drug resistance in cancer cells, and MRPs act as a potential target in cancer therapy. MRP-1 is identified as a GSSG transporter. Evidence has shown that inhibition on MRP activity promotes the accumulation of GSSG which is cytotoxic to endothelial cell tumors [160]. Sulfinosine has the potential to induce apoptosis and autophagy by decreasing GSH, generating ROS, and inhibiting P-pg and then sensitizes cancer cells to chemotherapies [161]. Modulation of GSH efflux is also a potential strategy to induce cell death in cancers. Staurosporine causes apoptosis in cancer cells associated with exporting cellular GSH [162]. Cancer cells are sensitized to cell death when intracellular GSH is depleted through stimulation of GSH efflux pumps [163]. Natural compound chrysin induces GSH efflux by MRPs to maintain the depleted GSH level and sensitizes cancer cells to chemotherapeutic agents like doxorubicin [164]. Verapamil derivatives can effectively kill cancer cell through leading to apoptosis with the mechanism of stimulating GSH efflux by MRPs [126].

\section{Conclusions}

In this review, accumulative evidence has demonstrated the important role of GSH depletion in the initiation of multiple forms of programmed cell death in cancers and we have highlighted the GSH-based strategies for cancer therapies. As mentioned, some agents trigger not only one type of programmed cell death solely but also multiple forms of cell death simultaneously through altering cellular GSH in cancer 
cells. While the crosstalks and interrelationships between the multiple forms of cell death induced by GSH modulation in cancer cells are still elusive, the exact death events along with GSH depletion in inducing cell death are still needed to be further explored. In the future work, a better understanding on the mechanism of GSH in triggering different forms of programmed cell death and whether GSH has a role in deciding cell fate will give more implications on the redox-based research concerning cancer therapeutics.

\section{Conflicts of Interest}

The authors declare no conflict of interest.

\section{Authors' Contributions}

Huanhuan Lv, Chenxiao Zhen, and Junyu Liu contributed equally.

\section{Acknowledgments}

This work was supported by the National Natural Science Fund of China (No. 81803032, No. 11872316, and No. 51777171), the Fundamental Research Funds for the Central Universities (No. 3102017OQD111), and the Northwestern Polytechnical University Foundation for Fundamental Research (No. 3102018JGC012).

\section{References}

[1] A. Meister and M. E. Anderson, "Glutathione," Annual Review of Biochemistry, vol. 52, no. 1, pp. 711-760, 1983.

[2] G. Wu, Y. Z. Fang, S. Yang, J. R. Lupton, and N. D. Turner, "Glutathione metabolism and its implications for health," The Journal of Nutrition, vol. 134, no. 3, pp. 489-492, 2004.

[3] H. Sies, "Glutathione and its role in cellular functions," Free Radical Biology and Medicine, vol. 27, no. 9-10, pp. 916921, 1999.

[4] J. N. Moloney and T. G. Cotter, "ROS signalling in the biology of cancer," Seminars in Cell \& Developmental Biology, vol. 80, pp. 50-64, 2018.

[5] S. Galadari, A. Rahman, S. Pallichankandy, and F. Thayyullathil, "Reactive oxygen species and cancer paradox: to promote or to suppress?," Free Radical Biology and Medicine, vol. 104, pp. 144-164, 2017.

[6] M. L. Circu and T. Y. Aw, "Reactive oxygen species, cellular redox systems, and apoptosis," Free Radical Biology and Medicine, vol. 48, no. 6, pp. 749-762, 2010.

[7] N. Traverso, R. Ricciarelli, M. Nitti et al., "Role of glutathione in cancer progression and chemoresistance," Oxidative Medicine and Cellular Longevity, vol. 2013, Article ID 972913, 10 pages, 2013.

[8] P. T. Schumacker, "Reactive oxygen species in cancer: a dance with the devil," Cancer Cell, vol. 27, no. 2, pp. 156-157, 2015.

[9] E. Hatem, N. el Banna, and M. E. Huang, "Multifaceted roles of glutathione and glutathione-based systems in carcinogenesis and anticancer drug resistance," Antioxidants \& Redox Signaling, vol. 27, no. 15, pp. 1217-1234, 2017.

[10] M. E. Anderson, "Glutathione: an overview of biosynthesis and modulation," Chemico-Biological Interactions, vol. 111112, pp. 1-14, 1998.
[11] T. P. Dalton, Y. Chen, S. N. Schneider, D. W. Nebert, and H. G. Shertzer, "Genetically altered mice to evaluate glutathione homeostasis in health and disease," Free Radical Biology and Medicine, vol. 37, no. 10, pp. 1511-1526, 2004.

[12] S. C. Lu, "Glutathione synthesis," Biochimica et Biophysica Acta (BBA) - General Subjects, vol. 1830, no. 5, pp. 31433153, 2013.

[13] P. Diaz Vivancos, T. Wolff, J. Markovic, F. V. Pallardó, and C. H. Foyer, "A nuclear glutathione cycle within the cell cycle," Biochemical Journal, vol. 431, no. 2, pp. 169-178, 2010.

[14] K. BRIVIBA, G. Fraser, H. Sies, and B. Ketterer, "Distribution of the monochlorobimane-glutathione conjugate between nucleus and cytosol in isolated hepatocytes," Biochemical Journal, vol. 294, no. 3, pp. 631-633, 1993.

[15] T. Söderdahl, M. Enoksson, M. Lundberg et al., "Visualization of the compartmentalization of glutathione and protein-glutathione mixed disulfides in cultured cells," Journal of Biological Chemistry, vol. 281, pp. 6372-6379, 2003.

[16] P. Diaz-Vivancos, A. de Simone, G. Kiddle, and C. H. Foyer, "Glutathione - linking cell proliferation to oxidative stress," Free Radical Biology and Medicine, vol. 89, pp. 1154-1164, 2015.

[17] M. J. Meredith and D. J. Reed, "Status of the mitochondrial pool of glutathione in the isolated hepatocyte," The Journal of Biological Chemistry, vol. 257, no. 7, pp. 3747-3753, 1982.

[18] C. Hwang, A. Sinskey, and H. Lodish, "Oxidized redox state of glutathione in the endoplasmic reticulum," Science, vol. 257, no. 5076, pp. 1496-1502, 1992.

[19] B. Morgan, D. Ezerina, T. N. E. Amoako, J. Riemer, M. Seedorf, and T. P. Dick, "Multiple glutathione disulfide removal pathways mediate cytosolic redox homeostasis," Nature Chemical Biology, vol. 9, no. 2, pp. 119-125, 2013.

[20] S. C. Lu, "Regulation of glutathione synthesis," Molecular Aspects of Medicine, vol. 30, no. 1-2, pp. 42-59, 2009.

[21] B. Morgan, "Reassessing cellular glutathione homoeostasis: novel insights revealed by genetically encoded redox probes," Biochemical Society Transactions, vol. 42, no. 4, pp. 979984, 2014.

[22] A. J. Meyer, T. Brach, L. Marty et al., "Redox-sensitive GFP in arabidopsis thaliana is a quantitative biosensor for the redox potential of the cellular glutathione redox buffer," The Plant Journal, vol. 52, no. 5, pp. 973-986, 2007.

[23] G. Calabrese, B. Morgan, and J. Riemer, "Mitochondrial glutathione: regulation and functions," Antioxidants \& Redox Signaling, vol. 27, no. 15, pp. 1162-1177, 2017.

[24] M. Marí, A. Morales, A. Colell, C. García-Ruiz, and J. C. Fernández-Checa, "Mitochondrial glutathione, a key survival antioxidant," Antioxidants \& Redox Signaling, vol. 11, no. 11, pp. 2685-2700, 2009.

[25] L. H. Lash, T. M. Visarius, J. M. Sall, W. Qian, and J. J. Tokarz, "Cellular and subcellular heterogeneity of glutathione metabolism and transport in rat kidney cells," Toxicology, vol. 130, no. 1, pp. 1-15, 1998.

[26] R. G. Schnellmann, S. M. Gilchrist, and L. J. Mandel, "Intracellular distribution and depletion of glutathione in rabbit renal proximal tubules," Kidney International, vol. 34, no. 2, pp. 229-233, 1988.

[27] K. Kojer, M. Bien, H. Gangel, B. Morgan, T. P. Dick, and J. Riemer, "Glutathione redox potential in the mitochondrial intermembrane space is linked to the cytosol and impacts the 
Mia40 redox state," The EMBO Journal, vol. 31, no. 14, pp. 3169-3182, 2012.

[28] T. Becker, M. Gebert, N. Pfanner, and M. van der Laan, "Biogenesis of mitochondrial membrane proteins," Current Opinion in Cell Biology, vol. 21, no. 4, pp. 484-493, 2009.

[29] T. Tatsuta, M. Scharwey, and T. Langer, "Mitochondrial lipid trafficking," Trends in Cell Biology, vol. 24, no. 1, pp. 44-52, 2014.

[30] S. Cogliati, J. A. Enriquez, and L. Scorrano, "Mitochondrial cristae: where beauty meets functionality," Trends in Biochemical Sciences, vol. 41, no. 3, pp. 261-273, 2016.

[31] L. H. Lash, "Role of glutathione transport processes in kidney function," Toxicology and Applied Pharmacology, vol. 204, no. 3, pp. 329-342, 2005.

[32] L. H. Lash, "Mitochondrial glutathione transport: physiological, pathological and toxicological implications," Chemico-Biological Interactions, vol. 163, no. 1-2, pp. 54-67, 2006.

[33] Z. Chen, D. A. Putt, and L. H. Lash, "Enrichment and functional reconstitution of glutathione transport activity from rabbit kidney mitochondria further evidence for the role of the dicarboxylate and 2-oxoglutarate carriers in mitochondrial glutathione transport," Archives of Biochemistry and Biophysics, vol. 373, no. 1, pp. 193-202, 2000.

[34] J. Markovic, C. Borras, A. Ortega, J. Sastre, J. Vina, and F. V. Pallardo, "Glutathione is recruited into the nucleus in early phases of cell proliferation," Journal of Biological Chemistry, vol. 282, no. 28, pp. 20416-20424, 2007.

[35] P. D. Vivancos, Y. Dong, K. Ziegler et al., "Recruitment of glutathione into the nucleus during cell proliferation adjusts whole-cell redox homeostasis in Arabidopsis thaliana and lowers the oxidative defence shield," The Plant Journal, vol. 64, no. 5, pp. 825-838, 2010.

[36] A. Holmgren, "Hydrogen donor system for Escherichia coli ribonucleoside-diphosphate reductase dependent upon glutathione," Proceedings of the National Academy of Sciences of the United States of America, vol. 73, no. 7, pp. 22752279, 1976.

[37] M. Valko, D. Leibfritz, J. Moncol, M. T. D. Cronin, M. Mazur, and J. Telser, "Free radicals and antioxidants in normal physiological functions and human disease," The International Journal of Biochemistry \& Cell Biology, vol. 39, no. 1, pp. 44-84, 2007.

[38] A. Holmgren, "The function of thioredoxin and glutathione in deoxyribonucleic acid synthesis," Biochemical Society Transactions, vol. 5, no. 3, pp. 611-612, 1977.

[39] M. Wang and R. J. Kaufman, "Protein misfolding in the endoplasmic reticulum as a conduit to human disease," Nature, vol. 529, no. 7586, pp. 326-335, 2016.

[40] D. Montero, C. Tachibana, J. Rahr Winther, and C. Appenzeller-Herzog, "Intracellular glutathione pools are heterogeneously concentrated," Redox Biology, vol. 1, no. 1, pp. 508-513, 2013.

[41] S. S. Cao and R. J. Kaufman, "Endoplasmic reticulum stress and oxidative stress in cell fate decision and human disease," Antioxidants \& Redox Signaling, vol. 21, no. 3, pp. 396413, 2014.

[42] M. E. Anderson, R. J. Bridges, and A. Meister, "Direct evidence for inter-organ transport of glutathione and that the non-filtration renal mechanism for glutathione utilization involves $\gamma$-glutamyl transpeptidase," Biochemical and
Biophysical Research Communications, vol. 96, no. 2, pp. 848-853, 1980.

[43] D. Häberle, A. Wahlländer, H. Sies, I. Linke, and C. Lachenmaier, "Assessment of the kidney function in maintenance of plasma glutathione concentration and redox state in anaesthetized rats," FEBS Letters, vol. 108, no. 2, pp. 335-340, 1979.

[44] R. Hahn, A. Wendel, and L. Flohé, “The fate of extracellular glutathione in the rat," Biochimica et Biophysica Acta (BBA) - General Subjects, vol. 539, no. 3, pp. 324-337, 1978.

[45] L. H. Lash and D. A. Putt, "Renal cellular transport of exogenous glutathione: heterogeneity at physiological and pharmacological concentrations," Biochemical Pharmacology, vol. 58, no. 5, pp. 897-907, 1999.

[46] X. Chen, H. Tsukaguchi, X. Z. Chen, U. V. Berger, and M. A. Hediger, "Molecular and functional analysis of SDCT2, a novel rat sodium-dependent dicarboxylate transporter," The Journal of Clinical Investigation, vol. 103, no. 8, pp. 1159-1168, 1999.

[47] M. Inoue and Y. Morino, "Direct evidence for the role of the membrane potential in glutathione transport by renal brushborder membranes," Journal of Biological Chemistry, vol. 260, no. 1, pp. 326-331, 1985.

[48] N. Ballatori, C. L. Hammond, J. B. Cunningham, S. M. Krance, and R. Marchan, "Molecular mechanisms of reduced glutathione transport: role of the MRP/CFTR/ABCC and OATP/SLC21A families of membrane proteins," Toxicology and Applied Pharmacology, vol. 204, no. 3, pp. 238-255, 2005.

[49] L. Li, T. K. Lee, P. J. Meier, and N. Ballatori, "Identification of glutathione as a driving force and leukotriene $\mathrm{C}_{4}$ as a substrate for oatp1, the hepatic sinusoidal organic solute transporter," Journal of Biological Chemistry, vol. 273, no. 26, pp. 16184-16191, 1998.

[50] A. K. Bachhawat, A. Thakur, J. Kaur, and M. Zulkifli, "Glutathione transporters," Biochimica et Biophysica Acta (BBA) - General Subjects, vol. 1830, no. 5, pp. 3154-3164, 2013.

[51] M. H. Hanigan, "Gamma-glutamyl transpeptidase: redox regulation and drug resistance," Advances in Cancer Research, vol. 122, pp. 103-141, 2014.

[52] S. Kumar, A. Kaur, B. Chattopadhyay, and A. K. Bachhawat, "Defining the cytosolic pathway of glutathione degradation in Arabidopsis thaliana: role of the ChaC/GCG family of $\gamma$ glutamyl cyclotransferases as glutathione-degrading enzymes and AtLAP1 as the Cys-Gly peptidase," Biochemical Journal, vol. 468, no. 1, pp. 73-85, 2015.

[53] A. Kumar, S. Tikoo, S. Maity et al., "Mammalian proapoptotic factor $\mathrm{ChaC} 1$ and its homologues function as $\gamma$-glutamyl cyclotransferases acting specifically on glutathione," EMBO Reports, vol. 13, no. 12, pp. 1095-1101, 2012.

[54] A. J. Oakley, T. Yamada, D. Liu, M. Coggan, A. G. Clark, and P. G. Board, "The identification and structural characterization of C7orf24 as $\gamma$-glutamyl cyclotransferase: an essential enzyme in the $\gamma$-glutamyl cycle," Journal of Biological Chemistry, vol. 283, no. 32, pp. 22031-22042, 2008.

[55] A. Kaur, R. Gautam, R. Srivastava et al., "ChaC2, an enzyme for slow turnover of cytosolic glutathione," Journal of Biological Chemistry, vol. 292, no. 2, pp. 638-651, 2017.

[56] C. Gorrini, I. S. Harris, and T. W. Mak, "Modulation of oxidative stress as an anticancer strategy," Nature Reviews Drug Discovery, vol. 12, no. 12, pp. 931-947, 2013. 
[57] A. L. Ortega, S. Mena, and J. M. Estrela, "Glutathione in cancer cell death," Cancers, vol. 3, no. 1, pp. 1285-1310, 2011.

[58] M. P. Murphy, "How mitochondria produce reactive oxygen species," Biochemical Journal, vol. 417, no. 1, pp. 1-13, 2009.

[59] L. Ouyang, Z. Shi, S. Zhao et al., "Programmed cell death pathways in cancer: a review of apoptosis, autophagy and programmed necrosis," Cell Proliferation, vol. 45, no. 6, pp. 487-498, 2012.

[60] Z. Su, Z. Yang, Y. Xu, Y. Chen, and Q. Yu, "Apoptosis, autophagy, necroptosis, and cancer metastasis," Molecular Cancer, vol. 14, no. 1, p. 48, 2015.

[61] S. Elmore, "Apoptosis: a review of programmed cell death," Toxicologic Pathology, vol. 29, no. 6, pp. 997-1003, 2012.

[62] Y. F. Zhao, C. Zhang, and Y. R. Suo, "MMPT as a reactive oxygen species generator induces apoptosis via the depletion of intracellular GSH contents in A549 cells," European Journal of Pharmacology, vol. 688, no. 1-3, pp. 6-13, 2012.

[63] R. Franco, M. I. Panayiotidis, and J. A. Cidlowski, "Glutathione depletion is necessary for apoptosis in lymphoid cells independent of reactive oxygen species formation," Journal of Biological Chemistry, vol. 282, no. 42, pp. 30452-30465, 2007.

[64] M. Khan, F. Yi, A. Rasul et al., "Alantolactone induces apoptosis in glioblastoma cells via GSH depletion, ROS generation, and mitochondrial dysfunction," IUBMB life, vol. 64, no. 9, pp. 783-794, 2012.

[65] J. S. Armstrong, K. K. Steinauer, B. Hornung et al., "Role of glutathione depletion and reactive oxygen species generation in apoptotic signaling in a human B lymphoma cell line," Cell Death \& Differentiation, vol. 9, no. 3, pp. 252263, 2002.

[66] L. Ghibelli, C. Fanelli, G. Rotilio et al., "Rescue of cells from apoptosis by inhibition of active GSH extrusion," The FASEB Journal, vol. 12, no. 6, pp. 479-486, 1998.

[67] C. L. Hammond, R. Marchan, S. M. Krance, and N. Ballatori, "Glutathione export during apoptosis requires functional multidrug resistance-associated proteins," The Journal of Biological Chemistry, vol. 282, no. 19, pp. 14337-14347, 2007.

[68] X. Zou, Z. Feng, Y. Li et al., "Stimulation of GSH synthesis to prevent oxidative stress-induced apoptosis by hydroxytyrosol in human retinal pigment epithelial cells: activation of Nrf2 and JNK-p62/SQSTM1 pathways," The Journal of Nutritional Biochemistry, vol. 23, no. 8, pp. 994-1006, 2012.

[69] M. J. Akhtar, M. Ahamed, H. A. Alhadlaq, and A. Alshamsan, "Nanotoxicity of cobalt induced by oxidant generation and glutathione depletion in MCF-7 cells," Toxicology in Vitro, vol. 40, pp. 94-101, 2017.

[70] G. Chen, Z. Chen, Y. Hu, and P. Huang, "Inhibition of mitochondrial respiration and rapid depletion of mitochondrial glutathione by $\beta$-phenethyl isothiocyanate: mechanisms for anti-leukemia activity," Antioxidants \& Redox Signaling, vol. 15, no. 12, pp. 2911-2921, 2011.

[71] M. L. Circu and T. Yee Aw, "Glutathione and apoptosis," Free Radical Research, vol. 42, no. 8, pp. 689-706, 2008.

[72] P. Guha, A. Dey, R. Sen, M. Chatterjee, S. Chattopadhyay, and S. K. Bandyopadhyay, "Intracellular GSH depletion triggered mitochondrial Bax translocation to accomplish resveratrol-induced apoptosis in the U937 cell line," Journal of Pharmacology and Experimental Therapeutics, vol. 336, no. 1, pp. 206-214, 2011.
[73] T. Honda, S. Coppola, L. Ghibelli et al., "GSH depletion enhances adenoviral bax-induced apoptosis in lung cancer cells," Cancer Gene Therapy, vol. 11, no. 4, pp. 249-255, 2004.

[74] P. Vandenabeele, L. Galluzzi, T. vanden Berghe, and G. Kroemer, "Molecular mechanisms of necroptosis: an ordered cellular explosion," Nature Reviews Molecular Cell Biology, vol. 11, no. 10, pp. 700-714, 2010.

[75] T. V. Berghe, A. Linkermann, S. Jouan-Lanhouet, H. Walczak, and P. Vandenabeele, "Regulated necrosis: the expanding network of non-apoptotic cell death pathways," Nature Reviews Molecular Cell Biology, vol. 15, no. 2, pp. 135-147, 2014.

[76] D. E. Christofferson and J. Yuan, "Necroptosis as an alternative form of programmed cell death," Current Opinion in Cell Biology, vol. 22, no. 2, pp. 263-268, 2010.

[77] L. Galluzzi and G. Kroemer, "Necroptosis: a specialized pathway of programmed necrosis," Cell, vol. 135, no. 7, pp. 1161-1163, 2008.

[78] H. Nagai, K. Matsumaru, G. Feng, and N. Kaplowitz, "Reduced glutathione depletion causes necrosis and sensitization to tumor necrosis factor-alpha-induced apoptosis in cultured mouse hepatocytes," Hepatology, vol. 36, no. 1, pp. 55-64, 2002.

[79] X. Xu, C. C. Chua, J. Kong et al., "Necrostatin-1 protects against glutamate-induced glutathione depletion and caspase-independent cell death in HT-22 cells," Journal of Neurochemistry, vol. 103, no. 5, pp. 2004-2014, 2007.

[80] A. K. Chauhan, K. J. Min, and T. K. Kwon, "RIP1-dependent reactive oxygen species production executes artesunateinduced cell death in renal carcinoma Caki cells," Molecular and Cellular Biochemistry, vol. 435, no. 1-2, pp. 15-24, 2017.

[81] X. Xie, Y. Zhao, C. Y. Ma et al., "Dimethyl fumarate induces necroptosis in colon cancer cells through GSH depletion/ ROS increase/MAPKs activation pathway," British Journal of Pharmacology, vol. 172, no. 15, pp. 3929-3943, 2015.

[82] M. S. Chen, S. F. Wang, C. Y. Hsu et al., "CHAC1 degradation of glutathione enhances cystine-starvation-induced necroptosis and ferroptosis in human triple negative breast cancer cells via the GCN2-eIF2 $\alpha$-ATF4 pathway," Oncotarget, vol. 8, no. 70, pp. 114588-114602, 2017.

[83] S. J. Dixon, K. M. Lemberg, M. R. Lamprecht et al., "Ferroptosis: an iron-dependent form of nonapoptotic cell death," Cell, vol. 149, no. 5, pp. 1060-1072, 2012.

[84] J. C. Reed and M. Pellecchia, "Ironing out cell death mechanisms," Cell, vol. 149, no. 5, pp. 963-965, 2012.

[85] W. S. Yang and B. R. Stockwell, "Ferroptosis: death by lipid peroxidation," Trends in Cell Biology, vol. 26, no. 3, pp. 165-176, 2016.

[86] X. Yu and Y. C. Long, "Crosstalk between cystine and glutathione is critical for the regulation of amino acid signaling pathways and ferroptosis," Scientific Reports, vol. 6, article 30033, no. 1, 2016.

[87] M. Gao, P. Monian, N. Quadri, R. Ramasamy, and X. Jiang, "Glutaminolysis and transferrin regulate ferroptosis," Molecular Cell, vol. 59, no. 2, pp. 298-308, 2015.

[88] X. Sui, R. Zhang, S. Liu et al., "RSL3 drives ferroptosis through GPX4 inactivation and ROS production in colorectal cancer," Frontiers in Pharmacology, vol. 9, p. 1371, 2018.

[89] J. P. Friedmann Angeli, M. Schneider, B. Proneth et al., "Inactivation of the ferroptosis regulator Gpx4 triggers acute 
renal failure in mice," Nature Cell Biology, vol. 16, no. 12, pp. 1180-1191, 2014.

[90] T. M. Seibt, B. Proneth, and M. Conrad, "Role of GPX4 in ferroptosis and its pharmacological implication," Free Radical Biology and Medicine, vol. 133, pp. 144-152, 2019.

[91] T. Hirschhorn and B. R. Stockwell, "The development of the concept of ferroptosis," Free Radical Biology and Medicine, vol. 133, pp. 130-143, 2019.

[92] W. S. Yang and B. R. Stockwell, "Synthetic lethal screening identifies compounds activating iron-dependent, nonapoptotic cell death in oncogenic-RAS-harboring cancer cells," Chemistry \& Biology, vol. 15, no. 3, pp. 234-245, 2008.

[93] W. S. Yang, R. SriRamaratnam, M. E. Welsch et al., "Regulation of ferroptotic cancer cell death by GPX4," Cell, vol. 156, no. 1-2, pp. 317-331, 2014.

[94] K. Shimada, R. Skouta, A. Kaplan et al., "Global survey of cell death mechanisms reveals metabolic regulation of ferroptosis," Nature Chemical Biology, vol. 12, no. 7, pp. 497-503, 2016.

[95] H. Miess, B. Dankworth, A. M. Gouw et al., "The glutathione redox system is essential to prevent ferroptosis caused by impaired lipid metabolism in clear cell renal cell carcinoma," Oncogene, vol. 37, no. 40, pp. 5435-5450, 2018.

[96] K. D'Herde and D. V. Krysko, "Ferroptosis: oxidized PEs trigger death," Nature Chemical Biology, vol. 13, no. 1, pp. 4-5, 2017.

[97] D. A. Stoyanovsky, Y. Y. Tyurina, I. Shrivastava et al., "Iron catalysis of lipid peroxidation in ferroptosis: regulated enzymatic or random free radical reaction?," Free Radical Biology and Medicine, vol. 133, pp. 153-161, 2019.

[98] V. E. Kagan, G. Mao, F. Qu et al., "Oxidized arachidonic and adrenic PEs navigate cells to ferroptosis," Nature Chemical Biology, vol. 13, no. 1, pp. 81-90, 2017.

[99] J. P. F. Angeli, R. Shah, D. A. Pratt, and M. Conrad, "Ferroptosis inhibition: mechanisms and opportunities," Trends in Pharmacological Sciences, vol. 38, no. 5, pp. 489498, 2017.

[100] C. Louandre, Z. Ezzoukhry, C. Godin et al., "Iron-dependent cell death of hepatocellular carcinoma cells exposed to sorafenib," International Journal of Cancer, vol. 133, no. 7, pp. 1732-1742, 2013.

[101] C. Louandre, I. Marcq, H. Bouhlal et al., “The retinoblastoma $(\mathrm{Rb})$ protein regulates ferroptosis induced by sorafenib in human hepatocellular carcinoma cells," Cancer Letters, vol. 356, no. 2, pp. 971-977, 2015.

[102] I. Dikic, T. Johansen, and V. Kirkin, "Selective autophagy in cancer development and therapy," Cancer Research, vol. 70, no. 9, pp. 3431-3434, 2010.

[103] D. R. Green and B. Levine, "To be or not to be? How selective autophagy and cell death govern cell fate," Cell, vol. 157, no. 1, pp. 65-75, 2014.

[104] G. Filomeni, D. De Zio, and F. Cecconi, "Oxidative stress and autophagy: the clash between damage and metabolic needs," Cell Death \& Differentiation, vol. 22, no. 3, pp. 377-388, 2015.

[105] G. Filomeni, E. Desideri, S. Cardaci, G. Rotilio, and M. R. Ciriolo, "Under the ROS: Thiol network is the principal suspect for autophagy commitment," Autophagy, vol. 6, no. 7, pp. 999-1005, 2010.

[106] H. Mancilla, R. Maldonado, K. Cereceda et al., "Glutathione depletion induces spermatogonial cell autophagy," Journal of Cellular Biochemistry, vol. 116, no. 10, pp. 2283-2292, 2015.

[107] E. Ogier-Denis and P. Codogno, "Autophagy: a barrier or an adaptive response to cancer," Biochimica et Biophysica Acta (BBA) - Reviews on Cancer, vol. 1603, no. 2, pp. 113-128, 2003 .

[108] W. Guo, Y. Zhao, Z. Zhang et al., "Disruption of xCT inhibits cell growth via the ROS/autophagy pathway in hepatocellular carcinoma," Cancer Letters, vol. 312, no. 1, pp. 55-61, 2011.

[109] E. Desideri, G. Filomeni, and M. R. Ciriolo, "Glutathione participates in the modulation of starvation-induced autophagy in carcinoma cells," Autophagy, vol. 8, no. 12, pp. 17691781, 2012.

[110] G. Seo, S. K. Kim, Y. J. Byun et al., "Hydrogen peroxide induces Beclin 1-independent autophagic cell death by suppressing the mTOR pathway via promoting the ubiquitination and degradation of Rheb in GSH-depleted RAW 264.7 cells," Free Radical Research, vol. 45, no. 4, pp. 389-399, 2011.

[111] R. Kang and D. Tang, "Autophagy and ferroptosis - what's the connection?," Current Pathobiology Reports, vol. 5, no. 2, pp. 153-159, 2017.

[112] C. Ott, J. Konig, A. Hohn, T. Jung, and T. Grune, "Reduced autophagy leads to an impaired ferritin turnover in senescent fibroblasts," Free Radical Biology and Medicine, vol. 101, pp. 325-333, 2016.

[113] S. Torii, R. Shintoku, C. Kubota et al., "An essential role for functional lysosomes in ferroptosis of cancer cells," Biochemical Journal, vol. 473, no. 6, pp. 769-777, 2016.

[114] Z. Wu, Y. Geng, X. Lu et al., "Chaperone-mediated autophagy is involved in the execution of ferroptosis," Proceedings of the National Academy of Sciences of the United States of America, vol. 116, no. 8, pp. 2996-3005, 2019.

[115] M. Gao, P. Monian, Q. Pan, W. Zhang, J. Xiang, and X. Jiang, "Ferroptosis is an autophagic cell death process," Cell Research, vol. 26, no. 9, pp. 1021-1032, 2016.

[116] W. Hou, Y. Xie, X. Song et al., "Autophagy promotes ferroptosis by degradation of ferritin," Autophagy, vol. 12, no. 8, pp. 1425-1428, 2016.

[117] N. Santana-Codina and J. D. Mancias, "The role of NCOA4mediated ferritinophagy in health and disease," Pharmaceuticals, vol. 11, no. 4, p. 114, 2018.

[118] J. D. Mancias, X. Wang, S. P. Gygi, J. W. Harper, and A. C. Kimmelman, "Quantitative proteomics identifies NCOA4 as the cargo receptor mediating ferritinophagy," Nature, vol. 509, no. 7498, pp. 105-109, 2014.

[119] W. E. Dowdle, B. Nyfeler, J. Nagel et al., "Selective VPS34 inhibitor blocks autophagy and uncovers a role for NCOA4 in ferritin degradation and iron homeostasis in vivo," Nature Cell Biology, vol. 16, no. 11, pp. 1069-1079, 2014.

[120] J. Du, T. Wang, Y. Li et al., "DHA inhibits proliferation and induces ferroptosis of leukemia cells through autophagy dependent degradation of ferritin," Free Radical Biology and Medicine, vol. 131, pp. 356-369, 2019.

[121] H. H. W. Chen and M. T. Kuo, "Role of glutathione in the regulation of cisplatin resistance in cancer chemotherapy," Metal-Based Drugs, vol. 2010, Article ID 430939, 7 pages, 2010.

[122] J. L. Roh, E. H. Kim, H. J. Jang, J. Y. Park, and D. Shin, "Induction of ferroptotic cell death for overcoming cisplatin resistance of head and neck cancer," Cancer Letters, vol. 381, no. 1, pp. 96-103, 2016. 
[123] K. J. Habermann, L. Grunewald, S. van Wijk, and S. Fulda, "Targeting redox homeostasis in rhabdomyosarcoma cells: GSH-depleting agents enhance auranofin-induced cell death," Cell Death \& Disease, vol. 8, no. 10, article e3067, 2017.

[124] M. Lo, Y. Z. Wang, and P. W. Gout, "The $\mathrm{x}_{\mathrm{c}}^{-}$cystine/ glutamate antiporter: a potential target for therapy of cancer and other diseases," Journal of Cellular Physiology, vol. 215, no. 3, pp. 593-602, 2008.

[125] J. Wang, B. Luo, X. Li et al., "Inhibition of cancer growth in vitro and in vivo by a novel ROS-modulating agent with ability to eliminate stem-like cancer cells," Cell Death \& Disease, vol. 8, no. 6, p. e2887, 2017.

[126] R. Barattin, T. Perrotton, D. Trompier et al., "Iodination of verapamil for a stronger induction of death, through GSH efflux, of cancer cells overexpressing MRP1," Bioorganic \& Medicinal Chemistry, vol. 18, no. 17, pp. 6265-6274, 2010.

[127] J. Lewerenz, S. J. Hewett, Y. Huang et al., "The cystine/ glutamate antiporter system $\mathrm{x}_{\mathrm{c}}{ }^{-}$in health and disease: from molecular mechanisms to novel therapeutic opportunities," Antioxidants \& Redox Signaling, vol. 18, no. 5, pp. 522-555, 2013.

[128] F. Wada, H. Koga, J. Akiba et al., "High expression of CD44v9 and $\mathrm{xCT}$ in chemoresistant hepatocellular carcinoma: potential targets by sulfasalazine," Cancer Science, vol. 109, no. 9, pp. 2801-2810, 2018.

[129] M. Toyoda, K. Kaira, Y. Ohshima et al., "Prognostic significance of amino-acid transporter expression (LAT1, ASCT2 and $\mathrm{xCT}$ ) in surgically resected tongue cancer," British Journal of Cancer, vol. 110, no. 10, pp. 2506-2513, 2014.

[130] E. Habib, K. Linher-Melville, H. X. Lin, and G. Singh, "Expression of $\mathrm{xCT}$ and activity of system $\mathrm{x}_{\mathrm{c}}$ - are regulated by NRF2 in human breast cancer cells in response to oxidative stress," Redox Biology, vol. 5, pp. 33-42, 2015.

[131] K. Sugano, K. Maeda, H. Ohtani, H. Nagahara, M. Shibutani, and $\mathrm{K}$. Hirakawa, "Expression of $\mathrm{xCT}$ as a predictor of disease recurrence in patients with colorectal cancer," Anticancer Research, vol. 35, no. 2, pp. 677-682, 2015.

[132] M. Lo, V. Ling, Y. Z. Wang, and P. W. Gout, "The $\mathrm{x}_{\mathrm{c}}^{-}$cystine/glutamate antiporter: a mediator of pancreatic cancer growth with a role in drug resistance," British Journal of Cancer, vol. 99, no. 3, pp. 464-472, 2008.

[133] S. Okuno, H. Sato, K. Kuriyama-Matsumura et al., "Role of cystine transport in intracellular glutathione level and cisplatin resistance in human ovarian cancer cell lines," British Journal of Cancer, vol. 88, no. 6, pp. 951-956, 2003.

[134] T. Ishimoto, O. Nagano, T. Yae et al., "CD44 variant regulates redox status in cancer cells by stabilizing the xCT subunit of system $\mathrm{x}_{\mathrm{c}}{ }^{-}$and thereby promotes tumor growth," Cancer Cell, vol. 19, no. 3, pp. 387-400, 2011.

[135] N. E. Savaskan, E. Hahnen, and I. Y. Eyüpoglu, “The $x_{c}$ cystine/glutamate antiporter $(\mathrm{xCT})$ as a potential target for therapy of cancer: yet another cytotoxic anticancer approach?," Journal of Cellular Physiology, vol. 220, no. 2, pp. 531-532, 2009.

[136] R. S. Chen, Y. M. Song, Z. Y. Zhou et al., "Disruption of xCT inhibits cancer cell metastasis via the caveolin-1/beta-catenin pathway," Oncogene, vol. 28, no. 4, pp. 599-609, 2009.

[137] M. H. Larraufie, W. S. Yang, E. Jiang, A. G. Thomas, B. S. Slusher, and B. R. Stockwell, "Incorporation of metabolically stable ketones into a small molecule probe to increase potency and water solubility," Bioorganic \& Medicinal Chemistry Letters, vol. 25, no. 21, pp. 4787-4792, 2015.

[138] J. L. Roh, E. H. Kim, H. Jang, and D. Shin, “Aspirin plus sorafenib potentiates cisplatin cytotoxicity in resistant head and neck cancer cells through xCT inhibition," Free Radical Biology and Medicine, vol. 104, pp. 1-9, 2017.

[139] M. Z. Ma, G. Chen, P. Wang et al., "Xc inhibitor sulfasalazine sensitizes colorectal cancer to cisplatin by a GSHdependent mechanism," Cancer Letters, vol. 368, no. 1, pp. 88-96, 2015.

[140] L. Sleire, B. S. Skeie, I. A. Netland et al., "Drug repurposing: sulfasalazine sensitizes gliomas to gamma knife radiosurgery by blocking cystine uptake through system $\mathrm{Xc}^{-}$, leading to glutathione depletion," Oncogene, vol. 34, no. 49, pp. 59515959, 2015.

[141] V. S. Narang, G. M. Pauletti, P. W. Gout, D. J. Buckley, and A. R. Buckley, "Sulfasalazine-induced reduction of glutathione levels in breast cancer cells: enhancement of growthinhibitory activity of Doxorubicin," Chemotherapy, vol. 53, no. 3, pp. 210-217, 2007.

[142] Z. Wang, Y. Ding, X. Wang et al., "Pseudolaric acid B triggers ferroptosis in glioma cells via activation of Nox4 and inhibition of xCT," Cancer Letters, vol. 428, pp. 21-33, 2018.

[143] B. N. Zhou, B. P. Ying, G. Q. Song, Z. X. Chen, J. Han, and Y. F. Yan, "Pseudolaric acids from pseudolarix kaempferi," Planta Medica, vol. 47, no. 1, pp. 35-38, 1983.

[144] Y. Chen, H. G. Shertzer, S. N. Schneider, D. W. Nebert, and T. P. Dalton, "Glutamate cysteine ligase catalysis," Journal of Biological Chemistry, vol. 280, no. 40, pp. 33766-33774, 2005.

[145] S. Shi, F. N. Hudson, D. Botta et al., "Over expression of glutamate cysteine ligase increases cellular resistance to $\mathrm{H} 2 \mathrm{O} 2$-induced DNA single-strand breaks," Cytometry Part A, vol. 71, no. 9, pp. 686-692, 2007.

[146] J. Y. Kim, J. H. Yim, J. H. Cho et al., “Adrenomedullin regulates cellular glutathione content via modulation of $\gamma$ glutamate-cysteine ligase catalytic subunit expression," Endocrinology, vol. 147, no. 3, pp. 1357-1364, 2006.

[147] M. Liu, Y. Zhao, and X. Zhang, "Knockdown of glutamate cysteine ligase catalytic subunit by siRNA causes the gold nanoparticles-induced cytotoxicity in lung cancer cells," Plos One, vol. 10, no. 3, article e0118870, 2015.

[148] Y. D. Hoang, A. P. Avakian, and U. Luderer, "Minimal ovarian upregulation of glutamate cysteine ligase expression in response to suppression of glutathione by buthionine sulfoximine," Reproductive Toxicology, vol. 21, no. 2, pp. 186-196, 2006.

[149] E. Debiton, J. C. Madelmont, J. Legault, and C. Barthomeuf, "Sanguinarine-induced apoptosis is associated with an early and severe cellular glutathione depletion," Cancer Chemotherapy and Pharmacology, vol. 51, no. 6, pp. 474-482, 2003.

[150] E. Ehrke, C. Arend, and R. Dringen, "3-bromopyruvate inhibits glycolysis, depletes cellular glutathione, and compromises the viability of cultured primary rat astrocytes," Journal of Neuroscience Research, vol. 93, no. 7, pp. 1138-1146, 2015.

[151] S. M. El Sayed, H. Baghdadi, M. Zolaly, H. H. Almaramhy, M. Ayat, and J. G. Donki, "The promising anticancer drug 3-bromopyruvate is metabolized through glutathione conjugation which affects chemoresistance and clinical practice: an evidence-based view," Medical Hypotheses, vol. 100, pp. 67-77, 2017. 
[152] S. Cardaci, E. Desideri, and M. R. Ciriolo, "Targeting aerobic glycolysis: 3-bromopyruvate as a promising anticancer drug," Journal of Bioenergetics and Biomembranes, vol. 44, no. 1, pp. 17-29, 2012.

[153] Y. H. Ko, B. L. Smith, Y. Wang et al., "Advanced cancers: eradication in all cases using 3-bromopyruvate therapy to deplete ATP," Biochemical and Biophysical Research Communications, vol. 324, no. 1, pp. 269-275, 2004.

[154] A. I. Amjad, R. A. Parikh, L. J. Appleman, E. R. Hahm, K. Singh, and S. V. Singh, "Broccoli-derived sulforaphane and chemoprevention of prostate cancer: from bench to bedside," Current Pharmacology Reports, vol. 1, no. 6, pp. 382-390, 2015.

[155] K. L. Cheung and A. N. Kong, "Molecular targets of dietary phenethyl isothiocyanate and sulforaphane for cancer chemoprevention," The AAPS Journal, vol. 12, no. 1, pp. 87-97, 2010.

[156] P. Gupta, B. Kim, S. H. Kim, and S. K. Srivastava, "Molecular targets of isothiocyanates in cancer: recent advances," Molecular Nutrition \& Food Research, vol. 58, no. 8, pp. 1685-1707, 2014.

[157] P. Gupta, S. E. Wright, S. H. Kim, and S. K. Srivastava, "Phenethyl isothiocyanate: a comprehensive review of anticancer mechanisms," Biochimica et Biophysica Acta (BBA) Reviews on Cancer, vol. 1846, no. 2, pp. 405-424, 2014.

[158] J. D. Clarke, R. H. Dashwood, and E. Ho, "Multi-targeted prevention of cancer by sulforaphane," Cancer Letters, vol. 269, no. 2, pp. 291-304, 2008.

[159] S. H. Huang, M. H. Hsu, S. C. Hsu et al., "Phenethyl isothiocyanate triggers apoptosis in human malignant melanoma A375.S2 cells through reactive oxygen species and the mitochondria-dependent pathways," Human \& Experimental Toxicology, vol. 33, no. 3, pp. 270-283, 2013.

[160] G. M. Gordillo, A. Biswas, S. Khanna, J. M. Spieldenner, X. Pan, and C. K. Sen, "Multidrug resistance-associated protein-1 (MRP-1)-dependent glutathione disulfide (GSSG) efflux as a critical survival factor for oxidant-enriched tumorigenic endothelial cells," Journal of Biological Chemistry, vol. 291, no. 19, pp. 10089-10103, 2016.

[161] M. Dačević, A. Isaković, A. Podolski-Renić et al., "Purine nucleoside analog - sulfinosine modulates diverse mechanisms of cancer progression in multi-drug resistant cancer cell lines," Plos One, vol. 8, no. 1, article e54044, 2013.

[162] M. L. Circu, S. Stringer, C. A. Rhoads, M. P. Moyer, and T. Y. Aw, "The role of GSH efflux in staurosporine-induced apoptosis in colonic epithelial cells," Biochemical Pharmacology, vol. 77, no. 1, pp. 76-85, 2009.

[163] M. Benlloch, A. Ortega, P. Ferrer et al., “Acceleration of glutathione efflux and inhibition of $\gamma$-glutamyltranspeptidase sensitize metastatic B16 melanoma cells to endotheliuminduced cytotoxicity," Journal of Biological Chemistry, vol. 280, no. 8, pp. 6950-6959, 2005.

[164] H. M. Brechbuhl, R. Kachadourian, E. Min, D. Chan, and B. J. Day, "Chrysin enhances doxorubicin-induced cytotoxicity in human lung epithelial cancer cell lines: the role of glutathione," Toxicology and Applied Pharmacology, vol. 258, no. 1, pp. 1-9, 2012. 


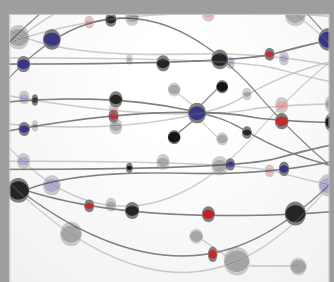

The Scientific World Journal
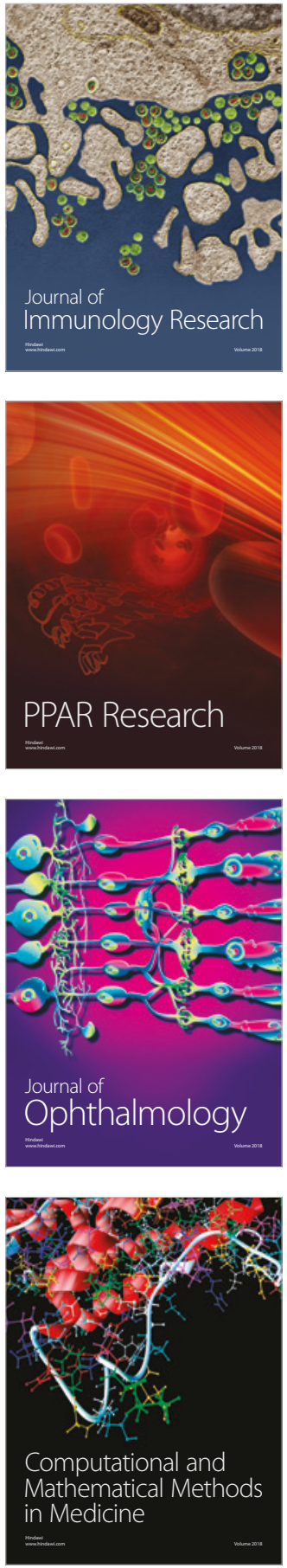

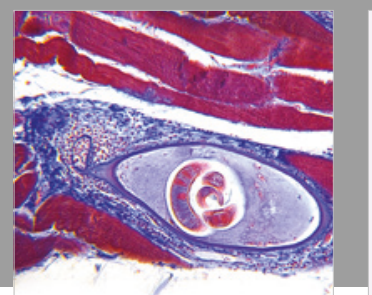

Gastroenterology Research and Practice

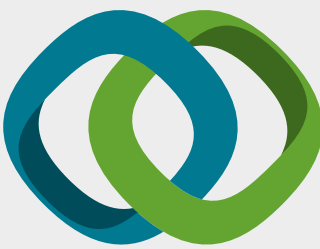

\section{Hindawi}

Submit your manuscripts at

www.hindawi.com
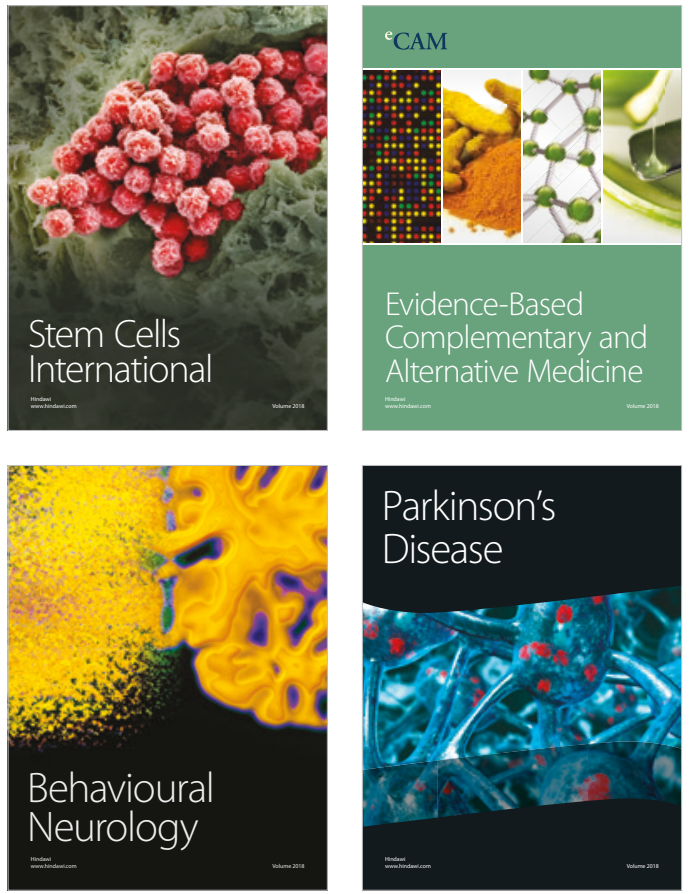

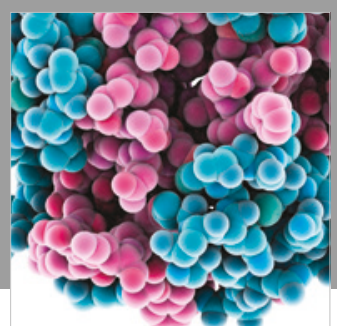

ournal of

Diabetes Research

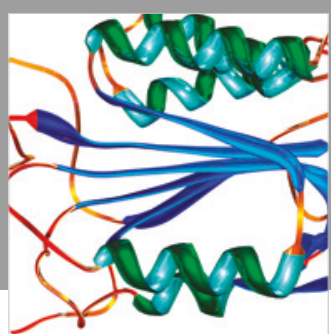

Disease Markers
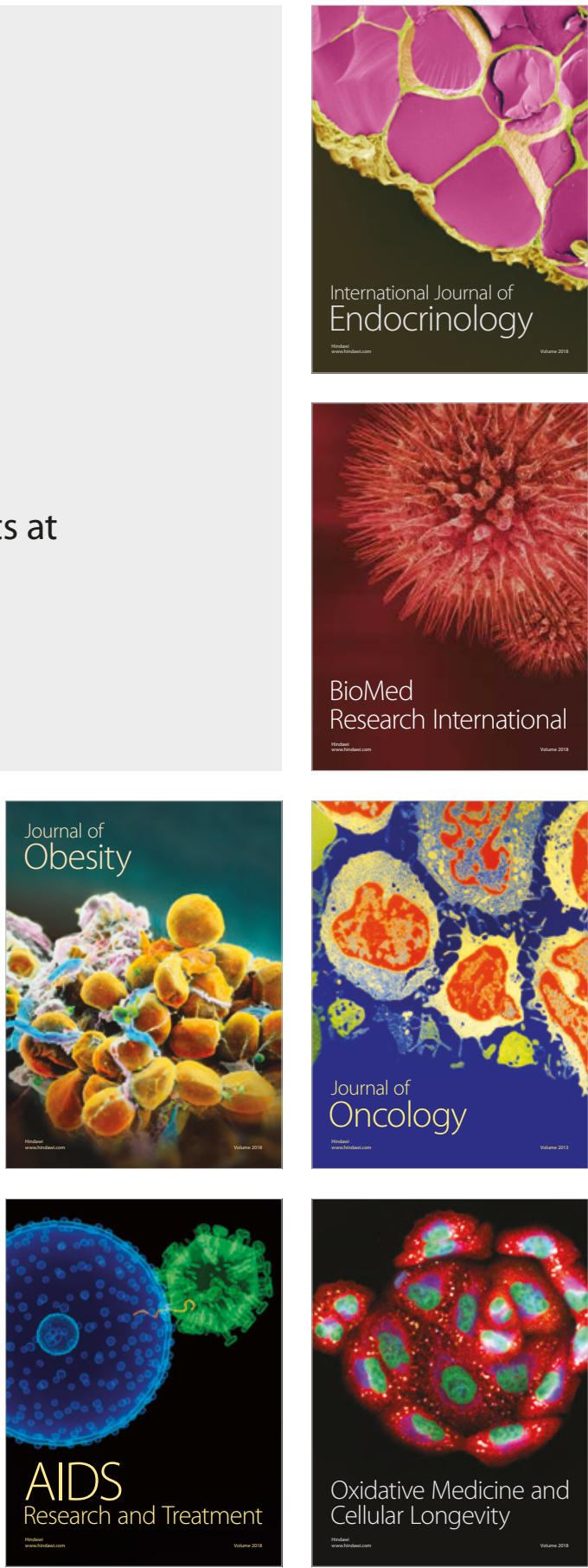